\title{
Multipotent Adult Progenitor Cells induce Regulatory T cells and promote their Suppressive Phenotype via TGF $\beta$ and Monocyte-dependent Mechanisms
}

\author{
Alice Valentin-Torres ( $\nabla$ avalentin-torres@athersys.com ) \\ Athersys Inc https://orcid.org/0000-0003-4399-6904 \\ Cora Day \\ Athersys Inc \\ Jennifer M Taggart \\ Athersys Inc \\ Nicholas Williams \\ Athersys Inc
}

Samantha R. Stubblefield

Athersys Inc

Anthony E. Ting

Athersys Inc

\section{Research}

Keywords: Tregs, MAPC, Stem cells, Monocytes

Posted Date: November 17th, 2020

DOI: https://doi.org/10.21203/rs.3.rs-108265/v1

License: (c) (i) This work is licensed under a Creative Commons Attribution 4.0 International License.

Read Full License 


\section{Abstract}

Background: Dysregulation of the immune system can initiate chronic inflammatory responses that exacerbate disease pathology. Multipotent adult progenitor cells (MAPC $\circledast$ cells), an adult, adherent bonemarrow derived stromal cell, have been observed to promote the resolution of uncontrolled inflammatory responses in a variety of clinical conditions including: acute ischemic stroke, acute myocardial infarction (AMI), graft vs host disease (GvHD), and acute respiratory distress syndrome (ARDS). One of the proposed mechanisms by which MAPC cells modulate immune responses is via the induction of regulatory $T$ cells (Tregs), however, the mechanism(s) involved remains to be fully elucidated.

Methods: To examine MAPC cell mediated Treg induction, peripheral mononuclear cells (PBMCs) were cocultured with MAPC cells at various PBMC: MAPC cell ratios. Treg frequencies and phenotype was determined by flow cytometry. The mechanisms involved in MAPC cell induction of Tregs were assessed using transforming growth factor $\beta$ (TGF) and indoleamine 2, 3 dioxygenase (IDO) inhibitors. Monocyte involvement in MAPC cell induction of Tregs was also explored.

Results: Herein, we demonstrate that, in an in vitro setting, MAPC cells increase Treg frequencies by promoting Treg proliferation and $\mathrm{CD} 4^{+} \mathrm{T}$ cell differentiation into Tregs. Moreover, MAPC cell-induced Tregs (miTregs) have a more suppressive phenotype characterized by increased expression of CTLA-4, HLA-DR, and PD-L1 and T cell suppression capacity. MAPC cells also promoted Treg activation by inducing CD45RA ${ }^{+}$CD45RO ${ }^{+}$transitional Tregs. Additionally, we identify TGF $\beta$ as an essential factor for Treg induction secreted by MAPC cells. Furthermore, IDO resulted in decreased Treg induction by MAPC cells demonstrating IDO involvement. Our studies also show that $\mathrm{CD} 14^{+}$monocytes play a critical role in Treg induction by MAPC cells.

Conclusions Our study describes MAPC cell dependent Treg phenotypic changes and provides evidence of potential mechanisms by which MAPC cells promote Treg differentiation.

\section{Background}

Tregs are indispensable players of immune regulation by maintaining self-tolerance and homeostasis. Tregs are characterized as natural Tregs (nTregs), which are developed in the thymus during embryonic state, or induced Tregs (iTregs) that arise from effector $T$ cells in the periphery, preferentially during inflammatory conditions (1). Tregs express both CD4 and CD25 surface antigens as well as the transcription factor, FoxP3, a critical gene involved in Treg development and function $(2,3)$. Treg deficient mice suffer fatal autoimmunity called "scurfy mice" (4). Similarly, humans born with dysfunctional FoxP3 develop an autoimmune syndrome called immunodysregulation polyendocrinopathy enteropathy X-linked (IPEX), which is characterized by severe enteropathy, endocrinopathy, and eczematous dermatitis $(5,6)$. Tregs control inflammation and modulate the immune system by several mechanisms which can be categorized as: (i) secretion of anti-inflammatory factors such as interleukin 10 (IL-10), interleukin 35 (IL35), and TGF $\beta$; (ii) metabolic disruption by cyclic adenosine monophosphate (CAMP), CD39, and CD73; 
(iii) inhibition of antigen presenting cell maturation; and (iv) induction of effector T cell death by interleukin 2 (IL-2) consumption and granzyme and perforin cytolysis $(7,8)$. Furthermore, Tregs express anti-inflammatory receptors, including cytotoxic T lymphocyte associated protein 4 (CTLA-4) and program cell death protein 1 ligand (PD-L1), that further support Treg immune regulatory properties. Due to its ability to reduce inflammation and modulate the immune system, the use of Tregs as therapy to treat autoimmune diseases is currently being explored $(9,10)$.

MAPC cells are adult bone marrow derived adherent cells with immunomodulatory properties that reduce inflammation by regulation of immune system functions (11). MAPC cells inhibit allogeneic T-cells in a mixed lymphocyte reaction (MLR) and suppress an allogeneic reaction between two mismatched lymphocyte populations $(12,13)$. MAPC cells inhibit allogeneic cell and memory response mediated T-cell proliferation in vitro in a dose-dependent manner (14). In vitro and in vivo studies have also demonstrated that MAPC cells suppress T cell homeostatic expansion driven by IL-7 via prostaglandin E2 (PGE-2) (15, 16). In rat models of traumatic brain injury or stroke, MAPC cell treatment significantly increases Treg frequencies in the spleen and blood (17-19). Concurrently, MAPC cell treatment reduces proliferation of both $\mathrm{CD} 4^{+}$and $\mathrm{CD} 8^{+}$T effector cells (17). MAPC cell administration also leads to a reduction of proinflammatory cytokines in a sheep model of hypoxic ischemia and rat models of stroke or traumatic brain injury (17-20).

In a clinical study evaluating the administration of MultiStem ${ }^{\circledR}$, a clinical grade product of MAPC cells, in patients receiving a liver transplant, a transient upregulation of Tregs in the blood was observed (21). MultiStem is currently under clinical evaluation to treat acute ischemic stroke (NCT03545607), ARDS (NCT02611609), and trauma. In the case of ischemic stroke, a Phase 2 clinical trial revealed that MultiStem treatment not only improved clinical outcomes but also reduced inflammation characterized by decreasing T effector cells and pro-inflammatory cytokines levels in the blood (22).

While MAPC cell-dependent induction of Tregs has been observed $(17,18,21,23)$, the mechanism(s) by which MAPC cells increase Tregs remain to be fully elucidated. In this study, we investigated MAPC cell induction of Tregs in vitro. These studies include examining the effects of MAPC cells on Treg proliferation, characterization of their suppressive phenotype, and analysis of their expression of CD45 isoforms. We also evaluated the involvement of factors secreted by MAPC cells in the induction of Tregs. These results provide greater insight into the mechanistic pathways in which MAPC cells modulate inflammation and immune responses in the setting of acute inflammatory diseases including ischemic stroke, ARDS, GvHD and AMI.

\section{Methods}

\section{Cell Culture}

MAPC cells were generated from donor's bone marrow aspirate as previously described $(14,24)$. Prior to use, MAPC cell phenotype was assessed by flow cytometry. As previously described, all MAPC cells used 
were over $90 \%$ positive for CD49c and CD90, whereas < $5 \%$ of the cells expressed HLA-DR and CD45 (14), thereby confirming that the MAPC cells used were in fact a homogenous population. Three different MAPC cell donors were used in this study. The population doublings for all MAPC cells used ranged from 20-35.

Human subjects' research approval was obtained from Western Institutional Review Board, Inc. (Puyallup, WA) and informed consent was obtained from healthy volunteers as appropriate. Peripheral blood mononuclear cells (PBMCs) were isolated from fresh blood of healthy volunteers (10 different donors) using Ficoll- Paque (GE Healthcare Life Sciences, Pittsburgh, PA) density gradient centrifugation as indicated by the manufacturer. Alternatively, isolated frozen PBMCs from healthy donors (2 different donors) were purchased from Precision for Medicine (Frederick, MD) and PPA Research (Johnson City, TN) and cultured as indicated by the manufacturer. PBMCs $\left(1 \times 10^{6}\right)$ were co-cultured with MAPC cells at different ratios in RPMI 1640 media supplemented with 10\% heat inactivated FBS and 1\% penicillin/streptomycin in a 24-well plate. At day 7 post co-culture, supernatants were collected and the percentage of Tregs was determined by flow cytometry.

Alternatively, CD14 ${ }^{+}$monocytes were depleted from PBMCs using anti-CD14 microbeads (Miltenyi Biotec, Auburn, CA) following the manufacturer's instructions. Similarly, CD $14^{+}$monocytes were isolated by positive selection using anti-CD14 microbeads (Miltenyi Biotec), whereas CD $4^{+} \mathrm{T}$ cells were isolated by negative selection using Dynabeads Untouched Human CD4 T cells kit (ThermoFisher, Waltham, MA). The purity of each cell type isolated was determined by staining cells with anti-CD14 (M5E2) PE, anti-CD3 (UCHT1) APC, and anti-CD4 (SK3) PerCpCy5.5 (BD Biosciences, San Diego, CA) as described below. Cell purity was over $90 \%$ for each isolated population. Isolated cells were plated as follows: $0.5 \times 10^{6} \mathrm{CD}^{+} \mathrm{T}$ cells and $0.25 \times 10^{6} \mathrm{CD} 14^{+}$monocytes $(2: 1) ; 0.5 \times 10^{6} \mathrm{CD} 4^{+} \mathrm{T}$ cells, $0.25 \times 10^{6} \mathrm{CD} 14^{+}$monocytes, and $0.25 \times 10^{6}$ MAPC cells $(2: 1: 1) ; 0.5 \times 10^{6} \mathrm{CD}^{+} \mathrm{T}$ cells, $0.25 \times 10^{6} \mathrm{CD} 14^{+}$monocytes, and $0.125 \times 10^{6} \mathrm{MAPC}$ cells (2:1:0.5). To enrich the CD45RA and CD45RO CD4 ${ }^{+} \mathrm{T}$ cell populations, $\mathrm{CD} 4^{+} \mathrm{T}$ cells were isolated using Dynabeads Untouched Human CD4 T cells kit followed by a positive selection of CD45RO ${ }^{+}$cells using CD45RO microbeads (Miltenyi Biotec) following manufacturer's instructions. Cells collected from the flow through were enriched for CD45RA. Cell purity was over $88 \%$ and $65 \%$ for CD45RO and CD 45RA $\mathrm{CD} 4^{+} \mathrm{T}$ cells, respectively.

\section{Flow Cytometry}

After supernatant collection, cells were washed with ice cold FACS buffer ( $2 \%$ heat inactivated FBS $2 \mathrm{mM}$ EDTA in D-PBS) for 5 minutes at $450 \mathrm{xg}$ on high brake. Cells were stained with BD Horizon Fixable Viability stain 780 (BD Biosciences) following manufacturer's instructions. After viability staining, cells were stained for surface markers using the following antibodies: anti-CD4 (RPA-T4) Pacific Blue, anti-CD3 (UCHT1) PerCP Cy5.5, anti-CD25 (2A3) PE, anti-HLA-DR (G46-6) BV650, and anti-PD-L1 (MIH1) BV786 (BD Biosciences) for 30 minutes on ice protected from light. Alternatively, to determine CD45RA and CD 45RO expression, cells were stained with anti-CD4 Pacific Blue, anti-CD3 PerCP Cy5.5, anti-CD25 PE, anti-HLADR BV650, anti-CD45RA (HI100) Alexa Fluor 700, and anti-CD45RO (uchl1) BV605 (BD Biosciences). 
After staining cell surface markers, cells were washed and fixed/permeabilized using FoxP3/Transcription Factor Staining Buffer Set (ThermoFisher) as directed by the manufacturer. Subsequent to the fixation/permeabilization, cells were stained using the following antibodies: antiFoxP3 (259D/C7) Alexa Fluor 647, anti-Ki67 (B56) BV510 (BD Biosciences), and anti-CTLA-4 (14D3) FITC (ThermoFisher).

To identify Tregs, cells were first gated based on lymphocyte size and granularity using forward and side scatter (FSC and SSC), followed by gating on single cells using FSC area versus FSC height. Live cells were selected based on the absence of Fixable Viability stain 780. $\mathrm{CD} 4^{+} \mathrm{T}$ cells were identified by their expression of $\mathrm{CD} 3$ and $\mathrm{CD} 4$. Tregs were identified as $\mathrm{CD}^{+} \mathrm{CD}^{+}{ }^{+} \mathrm{FoxP}^{+} \mathrm{CD} 25^{+}$.

To determine the expression of latent associated peptide (LAP) and glycoprotein-A repetitions predominant (GARP) on MAPC cells, MAPC cells were cultured for 7 days in RPMI media supplemented with $10 \%$ heat inactivated FBS and $1 \%$ penicillin/streptomycin. Cells were washed and stained for the surface expression of LAP and GARP using the following antibodies: anti-LAP (TW4-9E7) BV421 and antiGARP (7B11) PE-CF594 (BD Biosciences), as described above. Alternatively, LAP and GARP expression was determined on MAPC out of thaw.

To identify the primary source of IL-10, PBMCs were cultured with or without MAPC cells for 7 days in RPMI media supplemented with $10 \%$ heat inactivated FBS and $1 \%$ penicillin/streptomycin. GolgiStop ${ }^{\text {TM }}$ (BD Biosciences) was added to cultures according manufacturer's instructions ( $0.67 \mu \mathrm{L}$ of GolgiStop per $\mathrm{mL}$ of media) overnight ( 16-18hrs). Cells were stained with Fixable Viability Stain 780 to exclude dead cells, followed by surface staining with anti-CD14 Pacific Blue, anti-CD3 PerCP Cy5.5, anti-CD25 PE, and anti-CD127 (HIL-7R-M21) Alexa Fluor 647 as described above. Cells were permeabilized using FoxP3/Transcription Factor Staining Buffer Set as described above and stained with anti-IL-10 (JES319F1) PE-CF594. Intracellular IL-10 was assessed in CD $14^{+}$monocytes, CD $25^{+} \mathrm{CD} 127^{\text {low }} \mathrm{CD} 4^{+}$Tregs, and MAPC cells.

All samples were analyzed using a BD FACSCelesta flow cytometer equipped with a blue, violet, and red laser configuration. Data collected from these experiments were analyzed using FlowJo software (Ashland, Oregon). Spectral spillover and fluorescent compensation were generated using BDCompBeads sets containing polystyrene beads coupled with antibody specific to mouse, rat, or hamster Ig, $\mathrm{K}$ light chain and negative control beads (BD Biosciences). Positive expression was based on fluorescent minus one (FMO) controls.

\section{T Cell Suppression Assay}

To assess Treg suppressive function, isolated PBMCs were cultured alone or with MAPC cells at a 2:1 PBMC: MAPC cell ratio for 7 days as described above. At day 7, Tregs were isolated using EasySep ${ }^{\text {TM }}$ Human CD4 + CD127LowCD25 + Regulatory T cell isolation kit (STEMCELL Technologies, Cambridge, MA) following manufacturer's instructions. Over $85 \%$ of the cells isolated were Tregs based on their phenotypic profile $\left(\mathrm{CD}^{+} \mathrm{CD}^{+} \mathrm{CD}^{2} 5^{+}, \mathrm{FoxP}^{+}\right.$, and $\left.\mathrm{CD} 127^{\text {low }}\right)$ assessed by flow cytometry. Isolated Tregs 
were co-cultured with CellTrace Violet stain (ThermoFisher) labeled autologous PBMCs stimulated with anti-CD3/CD28 Dynabeads $\left(1 \times 10^{5}\right.$ beads/ml, ThermoFisher) in RPMI 1640 media supplemented with $10 \%$ heat inactivated FBS and $1 \%$ penicillin/streptavidin. At day 5 post stimulation, cells were stained with BD Horizon Fixable Viability stain 780, anti-CD3 PerCP Cy5.5, and anti-CD25 PE (BD Biosciences). Samples were analyzed by flow cytometry using BD FACSCelesta. Tregs were excluded based on their CD25 $5^{\text {hi }}$ expression and lack of CellTrace Violet stain. T cell proliferation was assessed by measuring CellTrace Violet stain dilution within the $\mathrm{CD}^{+} \mathrm{T}$ cell population.

\section{TGF $\beta$ and IDO inhibition experiments}

To inhibit TGF $\beta$ signaling, PBMCs were co-cultured with MAPC cells in the presence of SB 431542 (Tocris, Minneapolis, MN), a selective inhibitor of TGF $\beta$ receptor 1 at a concentration of $10 \mu \mathrm{M}$ (25). SB 431542 was dissolved in dimethyl sulfoxide (DMSO) at $50 \mathrm{mM}$ as indicated by the manufacturer. Vehicle controls were treated with equal amounts of DMSO.

IDO was inhibited using INCB024360, a potent and selective ID01 inhibitor (Cayman Chemical, Ann Arbor, $\mathrm{MI})$ added to PBMC: MAPC cell co-cultures at a concentration of $10 \mu \mathrm{M}(26)$. INCB024360 was dissolved in DMSO at $0.11 \mathrm{M}$ following manufacturer's guidelines. Vehicle controls received equal amounts of DMSO. Treg induction was determined by flow cytometry as described above.

\section{ELISA}

The levels of TGF $\beta$, LAP, and IL-10 in culture supernatants were measured using human Quantikine ELISA kits from R\&D Systems (Minneapolis, MN) following manufacturer's instructions.

\section{Statistical Analysis}

Data represent the mean \pm SD as indicated in figure legends. P-values were determined by One-way ANOVA with a Tukey's multiple comparison test, Student's $t$ Test, or Two-way ANOVA with Sidak's multiple comparison test using GraphPad Prism 8.4.2 (San Diego, CA).

\section{Results}

\section{Co-culture of PBMCs with MAPC cells increase Tregs}

In vivo and in vitro, MAPC cells have been shown to increase regulatory T cells (Tregs) $(17,18,21)$. However, the mechanisms by which MAPC cells augment Tregs remains to be fully understood. To understand and characterize MAPC cells induced Tregs (miTreg) in vitro, peripheral blood mononuclear cells (PBMCs) were co-cultured with MAPC cells at different PBMC: MAPC cell ratios. Since T cell activation can result in transient expression of FoxP3 and CD25 on effector T cells, our studies were performed in the absence of $\mathrm{T}$ cell stimulation (27). The percentage of Tregs $\left(\mathrm{CD} 3^{+} \mathrm{CD} 4^{+} \mathrm{CD} 25^{+} \mathrm{FoxP} 3^{+}\right.$) was determined by flow cytometry at day 7 (Fig. 1). As seen in vivo, MAPC cells increased the percentage of Tregs by approximately 2.7-fold at 2:1 and 2.5-fold at 4:1 PBMC: MAPC cell ratios, respectively 
(Fig. 1A). Further dilutions of MAPC cell concentration demonstrated that MAPC cell induction of Tregs is dose dependent (Fig. 1B). Increased FoxP3 and CD25 expression on Tregs have been shown to correlate with increased anti-inflammatory capacity (28-30). Thus, the FoxP3 and CD25 mean fluorescent intensity (MFI) within the Treg population was examined (Fig. 1C and D). Interestingly, miTregs displayed increased FoxP3 and CD25 expression than Tregs from PBMCs cultured alone. In addition, over $90 \%$ of miTregs were Helios positive and CD127 low, further confirming that these cells are indeed Tregs (Supplementary Fig. 1A and B).

To study whether MAPC cells can drive the differentiation of $\mathrm{CD} 4^{+} \mathrm{T}$ cells into Tregs, $\mathrm{CD} 25^{+}$cells were depleted using magnetic bead separation and CD25 negative PBMCs were co-cultured with MAPC cells. CD25 depletion was confirmed by flow cytometric analysis (data not shown). We found that MAPC cells increased the percent of Tregs by $2.6-$ fold, suggesting that MAPC cells can induce the conversion of CD $4^{+}$ T cells into Tregs (Supplemental Fig. 2A). Collectively, these data demonstrate that in the absence of stimulation, MAPC cells interactions with PBMCs result in the induction of Tregs.

\section{MAPC cells augment Tregs proliferation in vitro}

To examine if MAPC cells induce Treg expansion, Treg proliferation was determined by assessing the expression of Ki67 as a surrogate marker of proliferation in the presence or absence of MAPC cells (Fig. 1E). Indeed, miTregs showed elevated Ki67 expression than Tregs from PBMCs cultured alone. MAPC cells also increased Ki67 expression on Tregs when co-cultured with CD25 negative PBMCs (Supplemental Fig. 2B). Surprisingly, Ki67 induction by MAPC cells was restricted to the FoxP3 ${ }^{+}$Tregs $^{2}$ and not effector $\mathrm{CD}^{+}{ }^{+}$(FoxP3 ${ }^{-}$) T cells (Fig. 1F). Together, these data suggest that MAPC cells preferentially induce the expansion of Tregs but not effector $\mathrm{CD} 4^{+} \mathrm{T}$ cells, as previously reported (14). Increased Suppressive Phenotype And Function In Mitregs

Increased expression of CTLA-4, HLA-DR, and PD-L1 on Tregs has been shown to correlate with a potent suppressive phenotype (31-34). The expression of these markers on miTregs was assessed by flow cytometry and compared to Tregs from PBMCs (Fig. 2). miTregs had an increased expression of CTLA-4 (Fig. 2A), HLA-DR (Fig. 2B), and PD-L1 (Fig. 2C) compared to PBMC Tregs. MAPC cell induction of CTLA4, HLA-DR, and PD-L1 expression was restricted to Tregs and not effector cells (data not shown). HLA-DR expression was also increased by MAPC cells on Tregs when co-cultured with CD25 negative PBMCs (Supplemental Fig. 1C). To investigate the effects of MAPC cells on Treg suppressive function, a T cell suppression assay was performed (Fig. 2D). miTregs suppressed $\mathrm{T}$ cell proliferation more efficiently than PBMC derived Tregs in all Treg: PBMC ratios tested, correlating with an increased suppressive phenotype. Together, these data demonstrate that MAPC cells not only increases the frequency of Tregs and their proliferation but also its activation and suppressive status.

\section{MAPC cells activate Tregs thereby increasing CD45RA ${ }^{+} \mathrm{CD}^{4} 5 \mathrm{RO}^{+}$transitional population}


Isoforms of CD45, CD45RA and CD45RO are surrogate markers of naïve and memory $T$ cells respectively $(35,36)$. It has been proposed that upon activation, naïve CD45RA ${ }^{+} T$ cells upregulate CD45RO and HLADR and overtime, activated T cells lose their CD45RA expression, thus turning into an activated memory $T$ cell (CD45RO ${ }^{+} \mathrm{HLA}^{-D R^{+} \text {CD 45RA }}{ }^{-}$) (37-39). Approximately, $70-95 \%$ of Tregs are CD45RO ${ }^{+}$and the frequency of these cells increases with age (37-39). Furthermore, activation and proliferation of $\mathrm{CD}_{45 \mathrm{RA}^{+}}$Tregs causes loss of CD45RA expression and gain of CD45RO turning them into memory/activated Tregs $(37,40)$. To evaluate whether MAPC cells favorably induce activation and proliferation of naïve or memory Tregs, the expression of CD45RA and CD45RO on miTregs was determined (Fig. 3). As previously described, Tregs from PBMCs cultured alone preferentially expressed CD45RO; however, in the presence of MAPC cells, a portion of Tregs adopt a transitional phenotype $\left(\mathrm{CD}_{4} 5 \mathrm{RA}^{+} \mathrm{CD} 45 \mathrm{RO}^{+}\right)$(Fig. 3A) suggesting that MAPC cells are activating CD45RA ${ }^{+}$naïve Tregs. To characterize the activation and proliferation state of miTregs, the expression of Ki67, CTLA-4, and HLA-DR was assessed and compared among the $\mathrm{CD}_{4} 4 \mathrm{RA}^{+}$(naïve), $\mathrm{CD} 45 \mathrm{RO}^{+}$(memory), and $\mathrm{CD} 45 \mathrm{RA}^{+} \mathrm{RO}^{+}$ (transitional) Treg populations. MAPC cells increased the proliferation and activation of naïve, memory, and transitional Tregs. However, transitional Tregs (CD45RA ${ }^{+}$CD45RO $\left.{ }^{+}\right)$had elevated expression of Ki67, CTLA-4, and HLA-DR (Fig. 3B), correlating with the transitional activated phenotype described in effector T cells $(35,36)$. Together, these data suggest that MAPC cells activate and increase the proliferation of both naïve and memory Tregs, and activation of naïve Tregs leads to increased frequency of transitional $\mathrm{CD}^{2} 5 \mathrm{RA}^{+}$CD $45 \mathrm{RO}^{+}$Tregs.

To confirm that the CD45RA ${ }^{+}$CD 45RO $0^{+}$transitional Tregs arise from MAPC cell activation of CD45RA ${ }^{+}$ Treg population, both $\mathrm{CD} 45 \mathrm{RA}^{+}$and $\mathrm{CD} 45 \mathrm{RO}^{+} \mathrm{CD} 4^{+} \mathrm{T}$ cells were enriched using microbead isolation and co-cultured with isolated $\mathrm{CD} 14^{+}$monocytes and MAPC cells for 7 days (Supplementary Fig. 3). Co-culture of MAPC cells with either $\mathrm{CD} 45 \mathrm{RA}^{+}$or $\mathrm{CD} 45 \mathrm{RO}^{+} \mathrm{CD} 4^{+} \mathrm{T}$ cells and $\mathrm{CD} 14^{+}$monocytes resulted in increased Treg frequencies (Supplementary Fig. 3A). Additionally, MAPC cells increased Ki67 (Supplementary Fig. 3B) and HLA-DR (Supplementary Fig. 3C) expression on Tregs from co-cultures of both CD45RA ${ }^{+}$or $\mathrm{CD} 45 \mathrm{RO}^{+} \mathrm{CD}^{+} \mathrm{T}$ cells with $\mathrm{CD} 14^{+}$monocytes. As expected, $\mathrm{CD} 45 \mathrm{RA}^{+} \mathrm{CD} 45 \mathrm{RO}^{+}$transitional Tregs were only observed in co-cultures of MAPC with CD45RA ${ }^{+} \mathrm{CD} 4^{+} \mathrm{T}$ cells and $\mathrm{CD} 14^{+}$monocytes (Supplementary Fig. 3D), further confirming that transitional Tregs emerge from the CD45RA ${ }^{+}$Tregs and not CD45RO Tregs.

\section{MAPC cell induction of Tregs is TGF $\beta$ and IDO dependent}

When PBMCs and MAPC cells were co-cultured in Transwells ${ }^{\circledR}$, Treg induction was equivalent to the levels observed when cells were in direct contact, suggesting that MAPC cells promotes Tregs via soluble factors (Supplementary Fig. 2E). Transforming growth factor $\beta$ (TGF $\beta$ ) has been implicated as a strong Treg inducer both in vivo and in vitro (41-44). First, TGF $\beta$ and LAP levels within culture supernatants were assessed (Fig. 4A and B). Both TGF $\beta$ and LAP levels were elevated within the culture supernatants in the presence of MAPC cells when compared to PBMCs alone. Furthermore, TGF $\beta$ and LAP levels were also assessed in supernatants from MAPC cells cultured alone at equal MAPC cell numbers as 2:1 PBMC: 
MAPC cell ratio. The levels of TGF $\beta$ and LAP were equivalent to those seen in the 2:1 PBMC: MAPC cell supernatants, suggesting that MAPC cells is the main source of TGF $\beta$. TGF $\beta$ production is tightly regulated at a posttranscriptional level (45). Conversion of latent into mature TGF $\beta$ requires cleavage from LAP. Latent TGF $\beta$ binds to GARP, a type I transmembrane cell surface docking receptor $(46,47)$. Since LAP and GARP are associated with TGF $\beta$ maturation, the expression of LAP and GARP was assessed on MAPC cells (Fig. 4C). Approximately 80\% MAPC cells were positive for LAP, whereas $65 \%$ of MAPC cells were GARP positive. Given that supernatants of MAPC cell cultured alone have equivalent levels of TGF $\beta$ and LAP as the 2:1 co-cultures and that MAPC cells have elevated surface expression of LAP and GARP suggest that MAPC cells are the main source of TGF $\beta$ in these cultures.

Considering that MAPC cells secret high levels of TGF $\beta$, its role as a mechanism of action by which MAPC cells induce Tregs was explored. To assess whether TGF $\beta$ is involved in MAPC cell-induction of Tregs, PBMCs were co-culture with MAPC cells in the presence of SB 431542, a small molecule TGF $\beta$ type 1 receptor antagonist (Fig. 5). Blockade of TGF $\beta$ signaling completely abrogated MAPC cell induction of Tregs (Fig. 5A), suggesting that TGF $\beta$ is a critical component of the mechanism by which MAPC cells promote Tregs. Furthermore, Tregs induced in the presence of SB 431542 had lower Ki67 expression, suggesting less proliferation (Fig. 5B). The abrogation of TGF $\beta$ signaling also diminished the expression of CTLA-4, HLA-DR, and PD-L1 on miTregs, further reiterating the important role of TGF $\beta$ in the induction of Tregs by MAPC cells (Fig. 5C-E). TGF $\beta$ signaling blockade increased HLA-DR expression on PBMC Tregs, while the expression of CTLA-4 and PD-L1 remained unaltered. This could be due to overall increased HLA-DR expression on immune cells in the inhibitor treated conditions (data not shown).

In vitro, MAPC cells inhibit T cell proliferation by the secretion of indoleamine 2 3-dioxygenase (ID0) (14). Furthermore, IDO has been implicated as an important factor of Treg induction $(48,49)$. To determine if IDO is involved in MAPC cell induction of Tregs, PBMC and MAPC cells were co-culture in the presence of INCB024360, a selective ID01 inhibitor. IDO inhibition resulted in a partial reduction of Treg induction by MAPC cells, suggesting that IDO is involved in MAPC cell induction of Tregs but it is not the primary mechanism (Supplemental Fig. 4). While Ki67 was still induced in miTregs in the presence of INCB024360, it was reduced when compared to the vehicle treated control (Supplemental Fig. 4B). Similarly, CTLA-4 was also induced in the presence of the IDO inhibitor, however, it was diminished when compared to vehicle treated samples (Supplemental Fig. 4C). In the presence of IDO blockade, HLA-DR and PD-L1 expression on miTregs were also upregulated, however, it was mildly reduced in 2:1 PBMC: MAPC cell condition (Supplemental Fig. 4D), whereas no effect in PD-L1 expression was observed (Supplemental Fig. 4E). Similar results were obtained when PBMCs were co-cultured with MAPC cells in the presence of 1-L-MT, an IDO inhibitor (data not shown). Together, these data suggest that IDO is involved in MAPC cell induction of Tregs, however it is not essential.

\section{CD14 ${ }^{+}$monocytes are involved in MAPC cell induction of Tregs}

MAPC cells and mesenchymal stem cells (MSC) have been shown to modulate myeloid cell responses by skewing their phenotypic profile towards anti-inflammatory cells or "M2" (50-52). Anti-inflammatory 
myeloid cells are known to secrete factors such as IL-10, TGF 3 , IDO, and retinoic acid that drive Treg differentiation (53-55) Considering that monocytes can differentiate into dendritic cells and/or macrophages, and in PBMCs, the percentage of dendritic cells is very low (0.3-0.9\% of all leukocytes) while monocytes are more abundant ( $2-12 \%$ of leukocytes), the role of monocytes in MAPC cell induction of Tregs was investigated. To determine whether monocytes are indispensable for MAPC cell induction of Tregs, the percentage of Tregs was assessed in MAPC cell co-cultures with PBMCs in which CD14 ${ }^{+}$monocytes were depleted (Fig. 6). In the absence of CD14 ${ }^{+}$monocytes, MAPC cells induced Tregs, but, to a lesser extent than unfractionated PBMCs (Fig. 6A). Furthermore, while MAPC cells increased the expression of Ki67, CTLA-4, HLA-DR, and PD-L1 on Tregs induced in the absence of CD14 ${ }^{+}$monocytes, their expression levels were lower than the unfractionated control (Fig. 6B-E). Supernatant levels of TGF $\beta$ and LAP remained unaltered suggesting that MAPC is the primary source of TGF $\beta$ and LAP in these cultures and not monocytes (Supplementary Fig. 5A and 5B). These data demonstrate that CD14 ${ }^{+}$ monocytes are involved in MAPC cell induction of Tregs.

To further confirm the role of $\mathrm{CD} 14^{+}$monocytes in MAPC cell induction of Tregs, MAPC cell mediated Treg induction was examined in co-cultures of isolated $\mathrm{CD} 4^{+} \mathrm{T}$ cells and $\mathrm{CD} 14^{+}$monocytes (Fig. 7 ). Interestingly, MAPC cells significantly increased the percentage of Tregs within isolated $\mathrm{CD} 4^{+} \mathrm{T}$ cell and CD14 ${ }^{+}$monocyte co-cultures (Fig. 7A). In addition, miTregs had increased proliferation as shown by their Ki67 expression (Fig. 7B). Furthermore, their CTLA-4, HLA-DR and PD-L1 expression was also increased (Fig. 7C-E). Collectively, these data demonstrate that the mechanism by which MAPC cells induce Tregs is dependent on $\mathrm{CD} 14^{+}$monocytes.

IL-10 is a potent anti-inflammatory cytokine secreted by several immune cells including Tregs, monocytes, macrophages, and dendritic cells. To assess whether MAPC cells affect IL-10 secretion, IL-10 levels in PBMC: MAPC cell co-culture supernatants were measured by ELISA (Fig. 8A). Minimal IL-10 concentration was found in supernatants from PBMCs and MAPC cells cultured alone. Interestingly, PBMCs and MAPC cell co-cultures had elevated IL-10 levels. Analysis of supernatants collected from CD14-depleted: MAPC cell co-cultures demonstrated that IL-10 levels were reduced in the absence of CD $14^{+}$monocytes (Fig. 8B). Conversely, IL-10 levels on co-cultures of isolated CD4 ${ }^{+} \mathrm{T}$ cells, monocytes, and MAPC cells were comparable to those observed in PBMC: MAPC co-cultures, suggesting that the source of IL-10 is either $\mathrm{CD} 4^{+} \mathrm{T}$ cells or monocytes. To identify the immune cell responsible for IL-10 production, PBMC: MAPC cells were co-cultured for 7 days. At day 7, GolgiStop ${ }^{\text {TM }}$ was added to the cultures overnight, and IL10 was measured intracellularly by flow cytometry. IL- $10^{+}$cells were found to be CD $14^{+}$monocytes and not $\mathrm{CD} 4^{+} \mathrm{T}$ cells nor MAPC cells (Fig. 8D), confirming monocytes as the primary producer of IL-10 in these cultures.

\section{Discussion}

The capacity of MAPC cells to modulate inflammation in multiple models of injury and disease has been widely described $(11,12,14-19,22,56)$. MAPC cells control immune responses by secreting a milieu of 
factors with immunomodulatory properties, thus, restoring the inflammatory balance and promoting tissue repair $(14-16,57)$. Furthermore, MAPC cells have been demonstrated to increase the frequency of Tregs which are widely known for their capacity to control immune responses and induce tolerance. Herein, as illustrated on Fig. 9, we characterize the phenotype of miTregs and describe the mechanisms by which MAPC cells induce Tregs.

First, we observed that MAPC cells consistently increased the frequency of Tregs in a dose-dependent fashion. miTregs expressed higher levels of Foxp3 and CD25 per cell than PBMC Tregs. These data suggest that miTregs may be more potent immune regulators than PBMC Tregs, as elevated levels of FoxP3 Tregs have been linked with lower transplant rejection, increased suppressive activity, and higher secretion of IL-10 and TGF $\beta$ in a murine model of orthotropic corneal transplantation (28). Conversely, Tregs expressing low levels of CD25 have been associated with autoimmunity (29). Also, in mice, upregulation of CD25 expression on Tregs correlates with enhanced Treg function (30).

Co-cultures of MAPC cells with CD25-depleted PBMCs demonstrated that MAPC cells promote the differentiation of $\mathrm{CD} 4^{+} \mathrm{T}$ cells into Tregs. Moreover, in the presence of MAPC cells, Tregs expressed high levels of the proliferation marker Ki67, suggesting that MAPC cells also increase the frequency of Tregs by stimulating their proliferation. Conversely, increased Ki67 expression was restricted to Tregs and not effector T cells, as previously demonstrated in an in vitro model of homeostatic proliferation (14).

Phenotypical analysis of cell surface markers demonstrated that miTregs express higher levels of CTLA4, HLA-DR, and PD-L1 than PBMC Tregs. CTLA-4 is a potent regulator of T cell activation by competing with CD28 for the binding of the B7 costimulatory molecules CD80 and CD86 (30). In humans, Tregs expressing high levels of CTLA-4 have increased suppressive capacity than CTLA-4 low expressing counterparts $(33,42)$. HLA-DR ${ }^{+}$Tregs express higher levels of FoxP3 (31). In vitro, activation of HLA-DR ${ }^{-}$ Tregs induces HLA-DR expression $(31,39,58)$. Parallel comparison of HLA-DR ${ }^{+}$versus HLA-DR ${ }^{-}$Tregs demonstrated that HLA-DR ${ }^{+}$Tregs are more efficient suppressors, suggesting that HLA-DR expression defines a terminally differentiated Treg $(30,31)$. MAPC cell mediated induction of HLA-DR was restricted to the Treg population and no other cell types. Ligation of PD-1 with PD-L1 sends inhibitory signals, thereby downregulating immune activation. Tregs from PD-L1 ${ }^{-/-}$mice have been shown to have impaired suppressive capacity in vitro and in an in vivo model of nephrotoxic nephritis, suggesting that PD-L1 expression on Tregs is important for Treg suppressive function (59). Moreover, stimulation of CD4 ${ }^{+} \mathrm{T}$ cells with anti-CD3/CD28 in the presence of recombinant PD-L1 increases Tregs by promoting CD $4^{+} \mathrm{T}$ cell differentiation into Tregs and driving Treg expansion (60). Thus, the increased expression of CTLA-4, HLA-DR, and PD-L1 in miTregs further supports that MAPC cells induce a potent suppressive phenotype on Tregs. Using a $T$ cell suppression assay, it was confirmed that miTreg are indeed significantly more suppressive of $\mathrm{T}$ cell proliferation when compared to PBMC Tregs.

The CD45 isoforms CD45RA and CD45RO are used to identify resting (CD45RA ${ }^{+}$FoxP3 $^{+} \mathrm{CD}^{2} 5^{+}$) versus activated $\left(\mathrm{CD} 45 \mathrm{RO}^{+} \mathrm{FoxP}^{+} \mathrm{CD}^{+} 5^{+}\right)$Tregs $(37,40)$. Our studies demonstrated that MAPC cells increase 
the frequency of a transitional/recently activated Treg expressing both CD45RA and CD45RO. The transitional/recently activated Tregs arose from the CD45RA ${ }^{+}$Treg population and not from CD45RO ${ }^{+}$ Tregs. Detailed analysis of the phenotype of this transitional population provided evidence that these cells express higher levels of Ki67, correlating with an active proliferative state along with increased CTLA-4 and HLA-DR than the CD45RA ${ }^{+}$and $C D 45 R^{+}$counterparts, consistent with a recently activated phenotype. MAPC cells also increased the expression of Ki67, CTLA-4, and HLA-DR on both CD45RA ${ }^{+}$and $\mathrm{CD}_{45 \mathrm{RO}^{+}}$Tregs; however, consistent with an activated state, $\mathrm{CD} 45 \mathrm{RO}^{+}$Tregs have higher expression of these markers than CD45RA ${ }^{+}$Tregs.

MAPC cells secrete a variety of paracrine factors that can modulate the immune system including TGF $\beta$ and IDO $(14,61,62)$. The results of our studies demonstrate that TGF $\beta$ secreted by MAPC cells is a primary mechanism by which MAPC cells induce Tregs. Blockade of TGF $\beta$ signaling using SB 431542, a TGF $\beta$ receptor antagonist, significantly abrogated MAPC cell induction of Tregs. In the absence of TGF $\beta$ signaling, MAPC cells were less efficient at promoting Treg proliferation and expression of suppressive markers. In addition to TGF $\beta$ being a primary driver of MAPC cell induction of Tregs, IDO was also identified as a contributing factor. The inhibition of IDO, another factor secreted by MAPC cells, partially reduced Treg induction supporting IDO involvement in Treg induction by MAPC cells. Both TGF $\beta$ and IDO have been extensively identified as key factors secreted by tolerogenic dendritic cells that promote Treg differentiation (41, 44, 48, 49, 53-55). Indeed, TGF $\beta$ and IDO have been proposed as potential mechanisms by which MSCs induces Treg differentiation $(63,64)$. Herein, we demonstrate that these factors also play an important role in MAPC cell mediated Treg induction.

The role of monocytes in MAPC cell induction of Tregs was also explored. Depletion of CD14 ${ }^{+}$monocytes demonstrated that these cells are involved in MAPC cell induction of Treg proliferation and phenotypic markers and IL-10 secretion. These observations were confirmed by co-culture of isolated $\mathrm{CD} 4^{+} \mathrm{T}$ cells, CD14 ${ }^{+}$monocytes and MAPC cells. In this setting, MAPC cells supported Treg induction by increasing their proliferation and expression of a suppressive phenotype. The involvement of monocytes in the induction of Tregs by MSCs has been previously described $(65,66)$. Researchers demonstrated that MSCs skew monocytes towards an anti-inflammatory phenotype, thereby facilitating Treg differentiation (65). MAPC cells have also been demonstrated to induce a similar anti-inflammatory phenotype on myeloid cells in vitro (51) and in vivo (18). Flow cytometric analysis demonstrated that MAPC cells increased monocyte secretion of IL-10. IL-10 has been shown to enhance TGF $\beta$-induced Treg differentiation and suppressive capacity via STAT3 and Foxo1 (67).

\section{Conclusions}

MAPC cells have potent immunoregulatory properties under a variety of conditions including homeostatic proliferation, graft vs host disease, spinal cord injury, traumatic brain injury and ischemic stroke (14-19, 57). Herein, we provide evidence that demonstrates MAPC cell mediated induction of Tregs, cells that are known to play a key role in modulating immune responses in vitro and in vivo. Furthermore, 
characterization of miTregs reveals a more potent immunomodulatory phenotype and highlights a mechanistic pathway where MAPC cells may modulate immune responses under different clinical conditions.

\section{List Of Abbreviations}

MAPC cells: Multipotent adult progenitor cells

AMI: acute myocardial infarction

GvHD: graft versus host disease

ARDS: Acute respiratory distress syndrome

Tregs: Regulatory T cells

PBMCs: Peripheral blood mononuclear cells

miTregs: MAPC cell- induced Tregs

TGF $\beta$ : Transforming growth factor beta

IDO: Indoleamine 2,3 dioxygenase

CTLA-4: Cytotoxic T lymphocyte associated protein 4

PD-L1: Programmed death ligand 1

HLA-DR: Human leukocyte antigen DR isotype

nTregs: Natural Tregs

iTregs: Induced Tregs

CD: cluster of differentiation

IPEX: Immunodysregulation polyendocrinopathy enteropathy $x$-linked

IL-10: Interleukin 10

IL-35: Interleukin 35

cAMP: Cyclic adenosine monophosphate

IL-2: Interleukin 2

MLR: Mixed lymphocyte reaction 
PGE-2: Prostaglandin E2

FBS: fetal bovine serum

DMSO: dimethyl sulfoxide

LAP: Latent associated protein

GARP: glycoprotein-A repetitions predominant

MFI: Mean fluorescent intensity

MSC: mesenchymal stem cells

\section{Declarations}

\section{Ethics Approval}

The use of healthy donor approval was obtained from Western Institutional Review Board, Inc. (Puyallup, WA) and informed consent was obtained from healthy volunteers as appropriate.

\section{Consent for publication}

Not applicable.

\section{Data Availability}

The data supporting the findings of this study are available from the corresponding author upon reasonable request.

\section{Disclosure of Potential Conflicts of Interest}

Alice Valentin-Torres, Cora Day, Jennifer M. Taggart, and Anthony E. Ting are employees of Athersys, Inc. and are shareholders of Athersys, Inc. Nicholas Williams and Samantha R. Stubblefield were employees of Athersys, Inc. during their contribution to the work submitted herein, but are no longer at Athersys, Inc.; however, they hold shares at Athersys, Inc.

\section{Funding}

This study was funded by Athersys, Inc.

\section{Author Contributions:}

Alice Valentin-Torres: conception and design, collection and assembly of data, data analysis and interpretation, manuscript writing 
Cora Day: collection and data assembly, data analysis

Jen M. Taggart.: collection and data assembly, data analysis

Nicholas Williams: collection and data assembly, data analysis

Samantha R. Stubblefield Park: conception, data analysis

Anthony E. Ting: conception and design, manuscript writing, final approval of manuscript.

\section{Acknowledgements}

We thank Dr. Robert W. Mays and Dr. Valerie D. Roobrouck for their thoughtful review of this manuscript.

\section{References}

1. Curotto de Lafaille MA, Lafaille JJ. Natural and adaptive foxp3+ regulatory T cells: more of the same or a division of labor? Immunity. 2009;30(5):626-35.

2. Zheng Y, Rudensky AY. Foxp3 in control of the regulatory T cell lineage. Nat Immunol. 2007;8(5):45762.

3. Lin W, Haribhai D, Relland LM, Truong N, Carlson MR, Williams CB, et al. Regulatory T cell development in the absence of functional Foxp3. Nat Immunol. 2007;8(4):359-68.

4. Brunkow ME, Jeffery EW, Hjerrild KA, Paeper B, Clark LB, Yasayko SA, et al. Disruption of a new forkhead/winged-helix protein, scurfin, results in the fatal lymphoproliferative disorder of the scurfy mouse. Nat Genet. 2001;27(1):68-73.

5. Chatila TA, Blaeser F, Ho N, Lederman HM, Voulgaropoulos C, Helms C, et al. JM2, encoding a fork head-related protein, is mutated in X-linked autoimmunity-allergic disregulation syndrome. J Clin Invest. 2000;106(12):R75-81.

6. Bennett CL, Christie J, Ramsdell F, Brunkow ME, Ferguson PJ, Whitesell L, et al. The immune dysregulation, polyendocrinopathy, enteropathy, X-linked syndrome (IPEX) is caused by mutations of FOXP3. Nat Genet. 2001;27(1):20-1.

7. Zhao H, Liao X, Kang Y. Tregs: Where We Are and What Comes Next? Front Immunol. 2017;8:1578.

8. Meng X, Yang J, Dong M, Zhang K, Tu E, Gao Q, et al. Regulatory T cells in cardiovascular diseases. Nat Rev Cardiol. 2016;13(3):167-79.

9. Ferreira LMR, Muller YD, Bluestone JA, Tang Q. Next-generation regulatory T cell therapy. Nat Rev Drug Discov. 2019;18(10):749-69.

10. Romano M, Fanelli G, Albany CJ, Giganti G, Lombardi G. Past, Present, and Future of Regulatory T Cell Therapy in Transplantation and Autoimmunity. Front Immunol. 2019;10:43.

11. Auletta JJ, Cooke KR, Solchaga LA, Deans RJ, van't Hof W. Regenerative stromal cell therapy in allogeneic hematopoietic stem cell transplantation: current impact and future directions. Biol Blood 
Marrow Transplant. 2010;16(7):891-906.

12. Kovacsovics-Bankowski M, Streeter PR, Mauch KA, Frey MR, Raber A, van't Hof W, et al. Clinical scale expanded adult pluripotent stem cells prevent graft-versus-host disease. Cell Immunol. 2009;255(12):55-60.

13. Plessers J, Dekimpe E, Van Woensel M, Roobrouck VD, Bullens DM, Pinxteren J, et al. Clinical-Grade Human Multipotent Adult Progenitor Cells Block CD8+ Cytotoxic T Lymphocytes. Stem Cells Transl Med. 2016;5(12):1607-19.

14. Reading JL, Yang JH, Sabbah S, Skowera A, Knight RR, Pinxteren J, et al. Clinical-grade multipotent adult progenitor cells durably control pathogenic $T$ cell responses in human models of transplantation and autoimmunity. J Immunol. 2013;190(9):4542-52.

15. Carty F, Corbett JM, Cunha J, Reading JL, Tree TIM, Ting AE, et al. Multipotent Adult Progenitor Cells Suppress T Cell Activation in In Vivo Models of Homeostatic Proliferation in a Prostaglandin E2Dependent Manner. Front Immunol. 2018;9:645.

16. Reading JL, Vaes B, Hull C, Sabbah S, Hayday T, Wang NS, et al. Suppression of IL-7-dependent Effector T-cell Expansion by Multipotent Adult Progenitor Cells and PGE2. Mol Ther. 2015;23(11):1783-93.

17. Yang B, Hamilton JA, Valenzuela KS, Bogaerts A, Xi X, Aronowski J, et al. Multipotent Adult Progenitor Cells Enhance Recovery After Stroke by Modulating the Immune Response from the Spleen. Stem Cells. 2017;35(5):1290-302.

18. Walker PA, Bedi SS, Shah SK, Jimenez F, Xue H, Hamilton JA, et al. Intravenous multipotent adult progenitor cell therapy after traumatic brain injury: modulation of the resident microglia population. $\mathrm{J}$ Neuroinflammation. 2012;9:228.

19. Walker PA, Shah SK, Jimenez F, Gerber MH, Xue H, Cutrone R, et al. Intravenous multipotent adult progenitor cell therapy for traumatic brain injury: preserving the blood brain barrier via an interaction with splenocytes. Exp Neurol. 2010;225(2):341-52.

20. Jellema RK, Ophelders DR, Zwanenburg A, Nikiforou M, Delhaas T, Andriessen P, et al. Multipotent adult progenitor cells for hypoxic-ischemic injury in the preterm brain. $J$ Neuroinflammation. 2015;12:241.

21. Soeder Y, Loss M, Johnson CL, Hutchinson JA, Haarer J, Ahrens N, et al. First-in-Human Case Study: Multipotent Adult Progenitor Cells for Immunomodulation After Liver Transplantation. Stem Cells Transl Med. 2015;4(8):899-904.

22. Hess DC, Sila CA, Furlan AJ, Wechsler LR, Switzer JA, Mays RW. A double-blind placebo-controlled clinical evaluation of MultiStem for the treatment of ischemic stroke. Int J Stroke. 2014;9(3):381-6.

23. Eggenhofer E, Popp FC, Mendicino M, Silber P, Van't Hof W, Renner P, et al. Heart grafts tolerized through third-party multipotent adult progenitor cells can be retransplanted to secondary hosts with no immunosuppression. Stem Cells Transl Med. 2013;2(8):595-606.

24. Boozer S, Lehman N, Lakshmipathy U, Love B, Raber A, Maitra A, et al. Global Characterization and Genomic Stability of Human MultiStem, A Multipotent Adult Progenitor Cell. J Stem Cells. 
2009;4(1):17-28.

25. Hjelmeland MD, Hjelmeland AB, Sathornsumetee S, Reese ED, Herbstreith MH, Laping NJ, et al. SB431542, a small molecule transforming growth factor-beta-receptor antagonist, inhibits human glioma cell line proliferation and motility. Mol Cancer Ther. 2004;3(6):737-45.

26. Liu X, Shin N, Koblish HK, Yang G, Wang Q, Wang K, et al. Selective inhibition of IDO1 effectively regulates mediators of antitumor immunity. Blood. 2010;115(17):3520-30.

27. Kmieciak M, Gowda M, Graham L, Godder K, Bear HD, Marincola FM, et al. Human T cells express CD25 and Foxp3 upon activation and exhibit effector/memory phenotypes without any regulatory/suppressor function. J Transl Med. 2009;7:89.

28. Chauhan SK, Saban DR, Lee HK, Dana R. Levels of Foxp3 in regulatory T cells reflect their functional status in transplantation. J Immunol. 2009;182(1):148-53.

29. Ferreira RC, Simons HZ, Thompson WS, Rainbow DB, Yang X, Cutler AJ, et al. Cells with Treg-specific FOXP3 demethylation but low CD25 are prevalent in autoimmunity. J Autoimmun. 2017;84:75-86.

30. Chen X, Oppenheim JJ. Resolving the identity myth: key markers of functional CD4+FoxP3+ regulatory T cells. Int Immunopharmacol. 2011;11(10):1489-96.

31. Baecher-Allan C, Wolf E, Hafler DA. MHC class II expression identifies functionally distinct human regulatory T cells. J Immunol. 2006;176(8):4622-31.

32. Francisco LM, Salinas VH, Brown KE, Vanguri VK, Freeman GJ, Kuchroo VK, et al. PD-L1 regulates the development, maintenance, and function of induced regulatory T cells. J Exp Med. 2009;206(13):3015-29.

33. Read S, Malmstrom V, Powrie F. Cytotoxic T lymphocyte-associated antigen 4 plays an essential role in the function of CD25(+)CD4(+) regulatory cells that control intestinal inflammation. J Exp Med. 2000;192(2):295-302.

34. Takahashi T, Tagami T, Yamazaki S, Uede T, Shimizu J, Sakaguchi N, et al. Immunologic selftolerance maintained by CD25(+)CD4(+) regulatory T cells constitutively expressing cytotoxic $T$ lymphocyte-associated antigen 4. J Exp Med. 2000;192(2):303-10.

35. Prince HE, York J, Jensen ER. Phenotypic comparison of the three populations of human lymphocytes defined by CD45RO and CD45RA expression. Cell Immunol. 1992;145(2):254-62.

36. Summers KL, O'Donnell JL, Hart DN. Co-expression of the CD45RA and CD45RO antigens on T lymphocytes in chronic arthritis. Clin Exp Immunol. 1994;97(1):39-44.

37. Booth NJ, McQuaid AJ, Sobande T, Kissane S, Agius E, Jackson SE, et al. Different proliferative potential and migratory characteristics of human CD4+ regulatory $T$ cells that express either CD45RA or CD45RO. J Immunol. 2010;184(8):4317-26.

38. Hoffmann P, Eder R, Boeld TJ, Doser K, Piseshka B, Andreesen R, et al. Only the CD45RA+ subpopulation of $C D 4+C D 25$ high $T$ cells gives rise to homogeneous regulatory T-cell lines upon in vitro expansion. Blood. 2006;108(13):4260-7. 
39. Schaier M, Seissler N, Schmitt E, Meuer S, Hug F, Zeier M, et al. DR(high+)CD45RA(-)-Tregs potentially affect the suppressive activity of the total Treg pool in renal transplant patients. PLoS One. 2012;7(3):e34208.

40. Miyara M, Yoshioka Y, Kitoh A, Shima T, Wing K, Niwa A, et al. Functional delineation and differentiation dynamics of human CD4+ T cells expressing the FoxP3 transcription factor. Immunity. 2009;30(6):899-911.

41. Fu S, Zhang N, Yopp AC, Chen D, Mao M, Chen D, et al. TGF-beta induces Foxp3 + T-regulatory cells from CD 4 + CD25 - precursors. Am J Transplant. 2004;4(10):1614-27.

42. Chen W, Jin W, Hardegen N, Lei KJ, Li L, Marinos N, et al. Conversion of peripheral CD4+CD25- naive $T$ cells to $C D 4+C D 25+$ regulatory $T$ cells by TGF-beta induction of transcription factor Foxp3. J Exp Med. 2003;198(12):1875-86.

43. Luo X, Yang H, Kim IS, Saint-Hilaire F, Thomas DA, De BP, et al. Systemic transforming growth factorbeta 1 gene therapy induces Foxp3+ regulatory cells, restores self-tolerance, and facilitates regeneration of beta cell function in overtly diabetic nonobese diabetic mice. Transplantation. 2005;79(9):1091-6.

44. Kretschmer K, Apostolou I, Hawiger D, Khazaie K, Nussenzweig MC, von Boehmer H. Inducing and expanding regulatory T cell populations by foreign antigen. Nat Immunol. 2005;6(12):1219-27.

45. Miyazono K, Olofsson A, Colosetti P, Heldin $\mathrm{CH}$. A role of the latent TGF-beta 1-binding protein in the assembly and secretion of TGF-beta 1. EMBO J. 1991;10(5):1091-101.

46. Tran DQ, Andersson J, Wang R, Ramsey H, Unutmaz D, Shevach EM. GARP (LRRC32) is essential for the surface expression of latent TGF-beta on platelets and activated FOXP3+ regulatory T cells. Proc Natl Acad Sci U S A. 2009;106(32):13445-50.

47. Stockis J, Colau D, Coulie PG, Lucas S. Membrane protein GARP is a receptor for latent TGF-beta on the surface of activated human Treg. Eur J Immunol. 2009;39(12):3315-22.

48. Baban B, Chandler PR, Sharma MD, Pihkala J, Koni PA, Munn DH, et al. IDO activates regulatory T cells and blocks their conversion into Th17-like T cells. J Immunol. 2009;183(4):2475-83.

49. Yan Y, Zhang GX, Gran B, Fallarino F, Yu S, Li H, et al. IDO upregulates regulatory T cells via tryptophan catabolite and suppresses encephalitogenic $T$ cell responses in experimental autoimmune encephalomyelitis. J Immunol. 2010;185(10):5953-61.

50. DePaul MA, Palmer M, Lang BT, Cutrone R, Tran AP, Madalena KM, et al. Intravenous multipotent adult progenitor cell treatment decreases inflammation leading to functional recovery following spinal cord injury. Sci Rep. 2015;5:16795.

51. Ravanidis S, Bogie JFJ, Donders R, Deans R, Hendriks JJA, Stinissen P, et al. Crosstalk with Inflammatory Macrophages Shapes the Regulatory Properties of Multipotent Adult Progenitor Cells. Stem Cells Int. 2017;2017:2353240.

52. Busch SA, Horn KP, Silver DJ, Silver J. Overcoming macrophage-mediated axonal dieback following CNS injury. J Neurosci. 2009;29(32):9967-76. 
53. Unger WW, Laban S, Kleijwegt FS, van der Slik AR, Roep BO. Induction of Treg by monocyte-derived DC modulated by vitamin D3 or dexamethasone: differential role for PD-L1. Eur J Immunol. 2009;39(11):3147-59.

54. Raker VK, Domogalla MP, Steinbrink K. Tolerogenic Dendritic Cells for Regulatory T Cell Induction in Man. Front Immunol. 2015;6:569.

55. Takenaka MC, Quintana FJ. Tolerogenic dendritic cells. Semin Immunopathol. 2017;39(2):113-20.

56. Burrows GG, Van't Hof W, Reddy AP, Wilmarth PA, David LL, Raber A, et al. Solution-Phase Crosstalk and Regulatory Interactions Between Multipotent Adult Progenitor Cells and Peripheral Blood Mononuclear Cells. Stem Cells Transl Med. 2015;4(12):1436-49.

57. Jacobs SA, Pinxteren J, Roobrouck VD, Luyckx A, van't Hof W, Deans R, et al. Human multipotent adult progenitor cells are nonimmunogenic and exert potent immunomodulatory effects on alloreactive T-cell responses. Cell Transplant. 2013;22(10):1915-28.

58. Putnam AL, Brusko TM, Lee MR, Liu W, Szot GL, Ghosh T, et al. Expansion of human regulatory Tcells from patients with type 1 diabetes. Diabetes. 2009;58(3):652-62.

59. Neumann K, Ostmann A, Breda PC, Ochel A, Tacke F, Paust HJ, et al. The co-inhibitory molecule PD$\mathrm{L} 1$ contributes to regulatory $\mathrm{T}$ cell-mediated protection in murine crescentic glomerulonephritis. Sci Rep. 2019;9(1):2038.

60. DiDomenico J, Lamano JB, Oyon D, Li Y, Veliceasa D, Kaur G, et al. The immune checkpoint protein PD-L1 induces and maintains regulatory T cells in glioblastoma. Oncoimmunology. 2018;7(7):e1448329.

61. Highfill SL, Kelly RM, O'Shaughnessy MJ, Zhou Q, Xia L, Panoskaltsis-Mortari A, et al. Multipotent adult progenitor cells can suppress graft-versus-host disease via prostaglandin E2 synthesis and only if localized to sites of allopriming. Blood. 2009;114(3):693-701.

62. Luo M, Liu Z, Hao H, Lu T, Chen M, Lei M, et al. High glucose facilitates cell cycle arrest of rat bone marrow multipotent adult progenitor cells through transforming growth factor-beta1 and extracellular signal-regulated kinase 1/2 signalling without changing Oct4 expression. Clin Exp Pharmacol Physiol. 2012;39(10):843-51.

63. Melief SM, Geutskens SB, Fibbe WE, Roelofs H. Multipotent stromal cells skew monocytes towards an anti-inflammatory interleukin-10-producing phenotype by production of interleukin-6. Haematologica. 2013;98(6):888-95.

64. Azevedo RI, Minskaia E, Fernandes-Platzgummer A, Vieira AIS, da Silva CL, Cabral JMS, et al. Mesenchymal stromal cells induce regulatory $T$ cells via epigenetic conversion of human conventional CD4 T cells in vitro. Stem Cells. 2020.

65. Melief SM, Schrama E, Brugman MH, Tiemessen MM, Hoogduijn MJ, Fibbe WE, et al. Multipotent stromal cells induce human regulatory $T$ cells through a novel pathway involving skewing of monocytes toward anti-inflammatory macrophages. Stem Cells. 2013;31(9):1980-91.

66. Negi N, Griffin MD. Effects of mesenchymal stromal cells on regulatory T cells: Current understanding and clinical relevance. Stem Cells. 2020. 

of Human Induced Regulatory T Cells via STAT3 and Foxo1. J Immunol. 2015;195(8):3665-74.

\section{Figures}
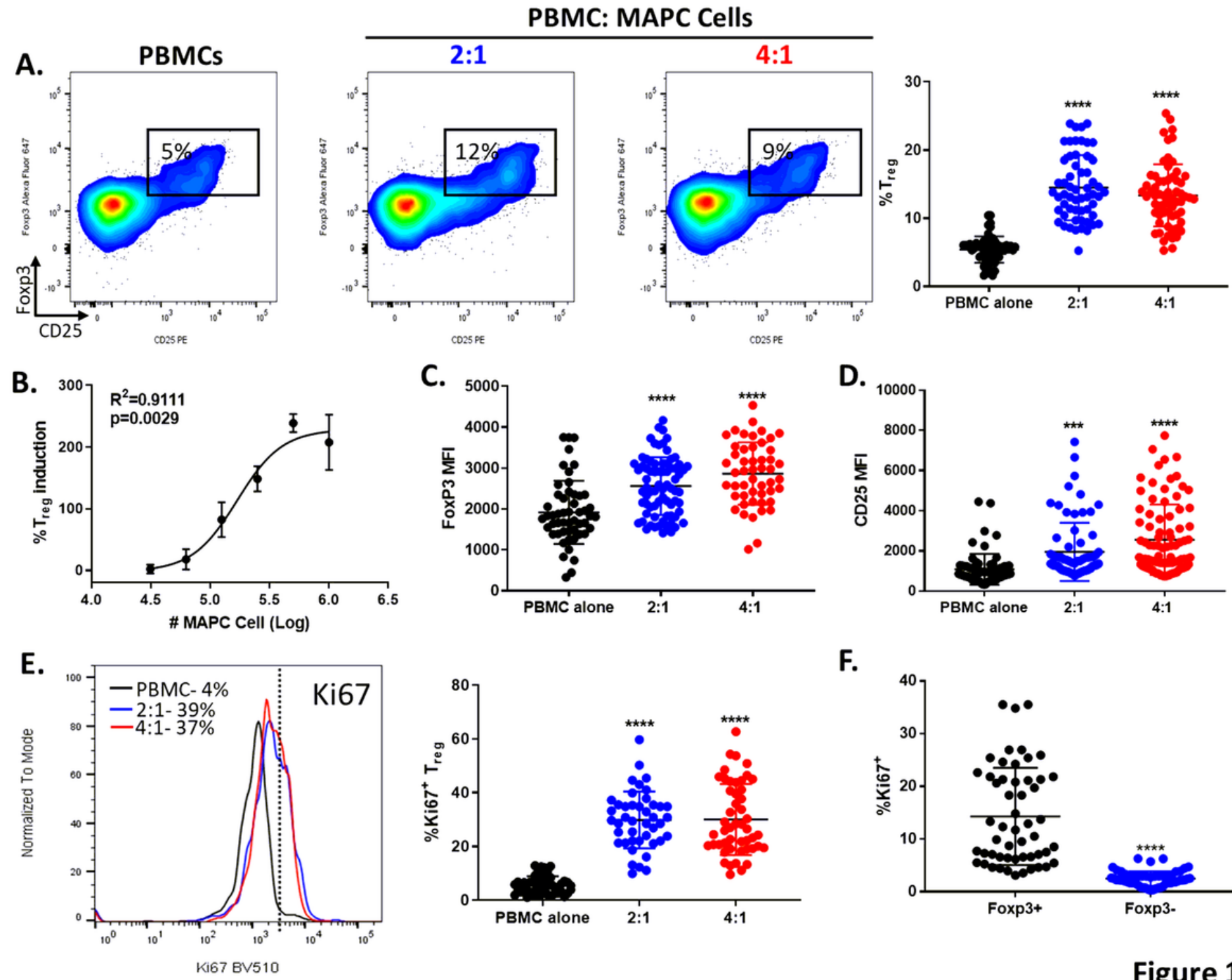

F.

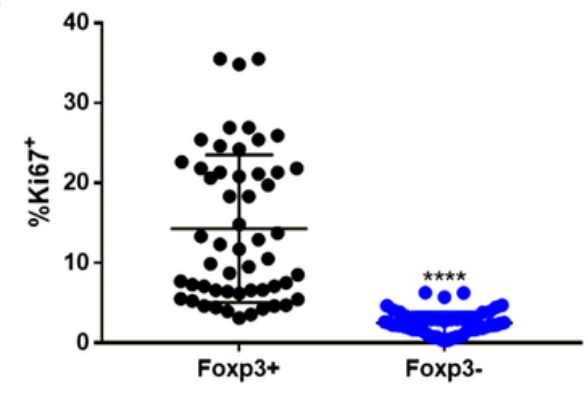

Figure 1

Figure 1

Co-culturing PBMCs and MAPC cells increase Treg frequency. (A) Representative dot plots depicting the percentages of Tregs (CD3+ CD4+ FoxP3+ CD25+) in PBMC alone and PBMCs co-cultured with MAPC cells for 7 days (2:1 and 4:1 PBMC: MAPC ratios). Graph shows quantification of MAPC cell dependent Treg induction. Each symbol represents one $n$ from multiple independent experiments. (B) Dose dependent curve of Treg induction. Quantification of (C) FoxP3 and (D) CD25 MFI on Tregs. (E) Representative histogram depicting Ki67 expression on Tregs from PBMC (black line), 2:1 (blue line), and 4:1 (red line) co-cultures. FMO shown as dotted line. Numbers represent the percent Ki67 positive within 
the Treg population. Graph shows quantification of Ki67 expression on Tregs. (F) Ki67 expression on FoxP3 positive (black) and FoxP3 negative (blue) population from 2:1 PBMC: MAPC cell co-cultures. Pvalue was determined by unpaired t-test. Data represent mean \pm SD from pooled samples of multiple independent experiments. P-values were determined by One-way ANOVA with a Tukey's multiple comparison test reference to the control PBMC alone $(* \star \star * p<0.0001$ and $* \star \star x<0.001)$.
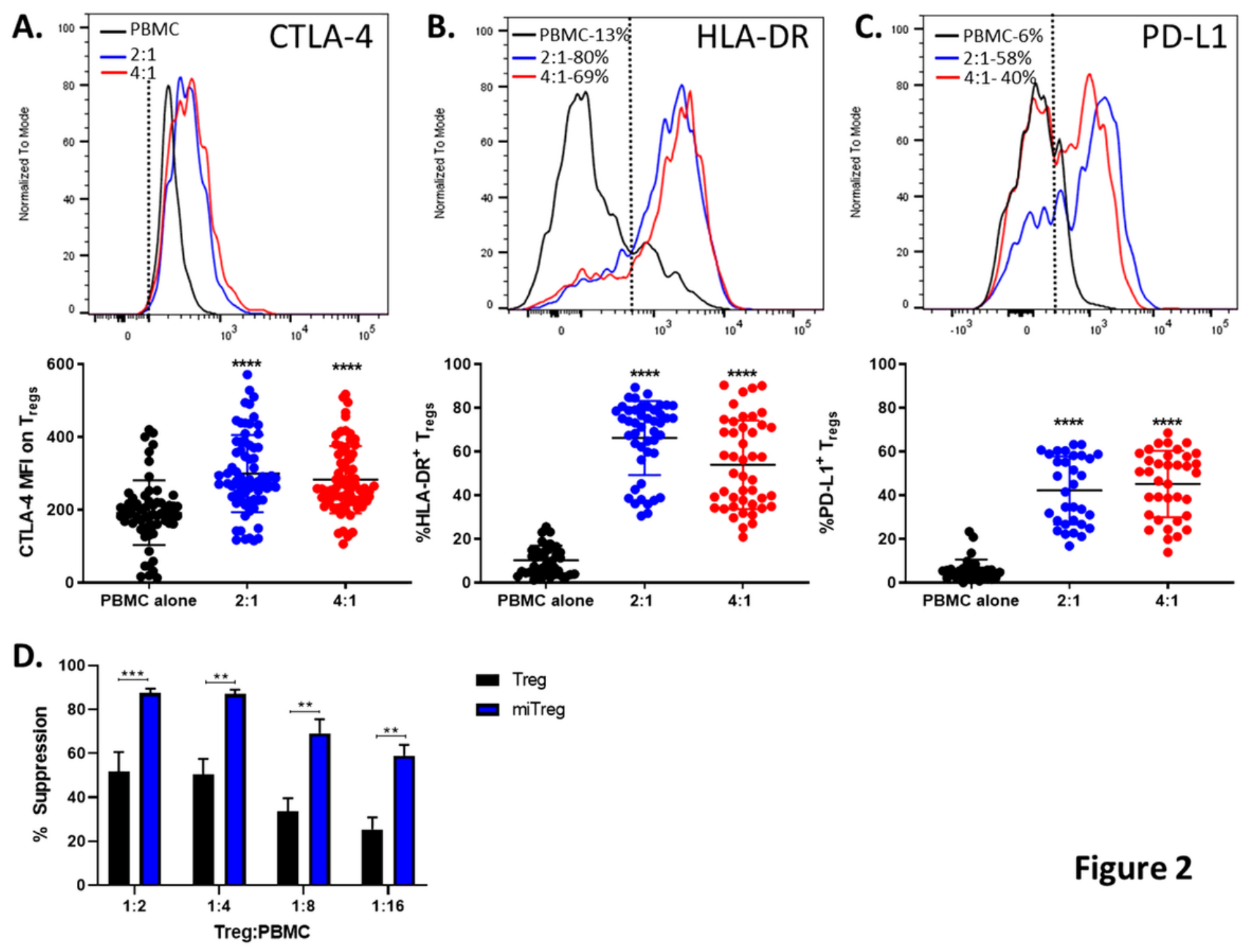

Figure 2

Figure 2

MAPC cells increase Treg suppressive phenotype and function capacity. Representative histogram depicting (A) CTLA-4, (B) HLA-DR, and (C) PD-L1 expression on Tregs from PBMC (black line), 2:1 (blue line), and 4:1 (red line) 7-day co-cultures. FMO shown as dotted line. Numbers represent the percent positive of corresponding marker within the Treg population. Graphs showing quantification of CTLA-4 (MFI), HLA-DR, and PD-L1 expression on Tregs. (D) Quantification of suppression of T cell proliferation by Tregs (black) or miTregs (blue) normalized to percent suppression. Data comprises 6 independent experiments from 6 healthy individual blood donors. Statistical analysis was performed using One-way 
ANOVA with a Tukey's multiple comparison test reference to the control PBMC alone $(* \star \star \star p<0.0001$, $\star \star \star x<0.001$, and $\left.{ }^{* *} p<0.01\right)$.

PBMC:MAPC Cells
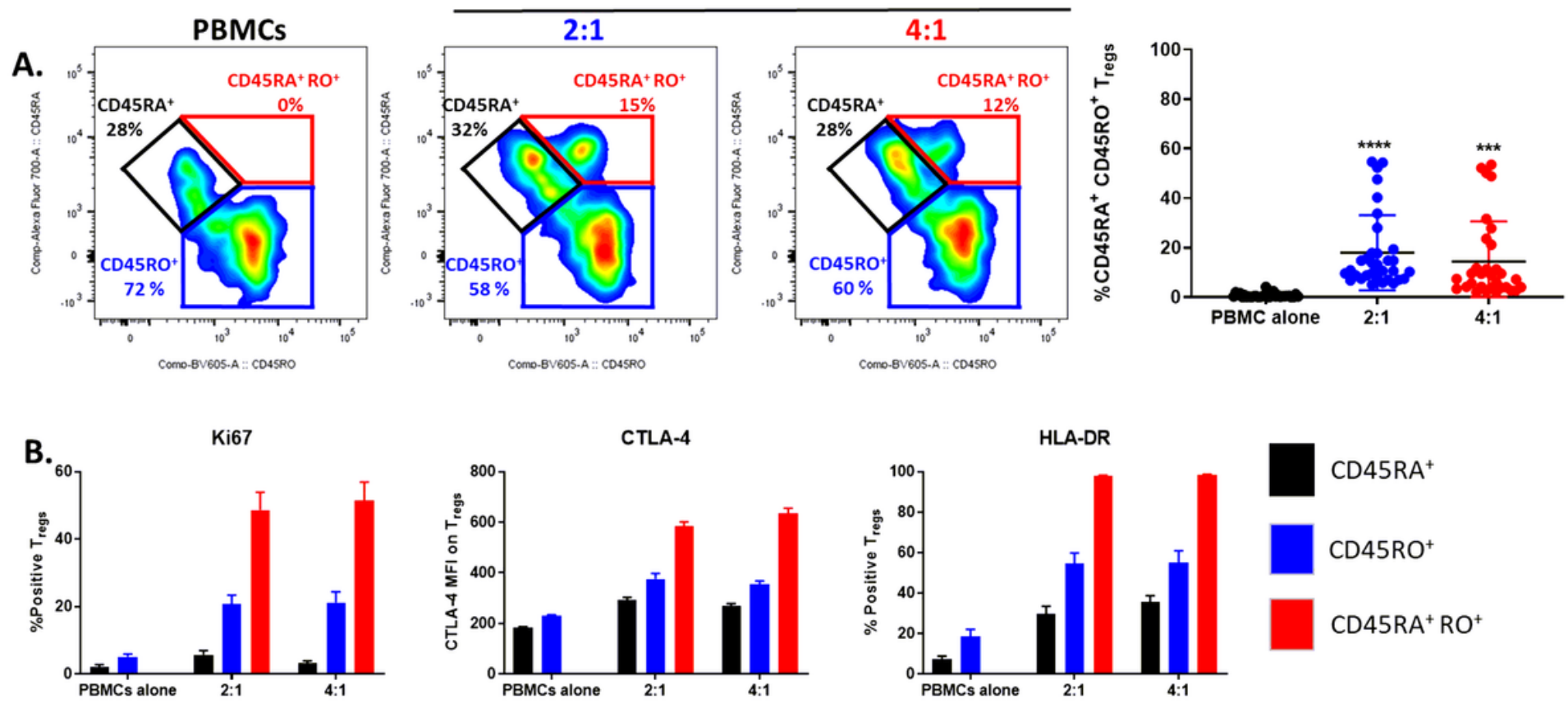

Figure 3

\section{Figure 3}

MAPC cells activate Tregs by increasing CD45RA+ CD45RO+ transitional cells. (A). Representative dot plots depicting CD45RA and CD45RO expression on Tregs from PBMC, 2:1, and 4:1 PBMC: MAPC cell 7day co-cultures. Numbers represent the percent positive cells within the Treg population. Graph represents quantification of CD45RA+ CD45RO+ (transitional) frequencies within the Treg population. (B) Ki67, CTLA-4, and HLA-DR expression on CD45RA+ (black), CD45RO+ (blue), and CD45RA+ RO+ (red) Tregs. Data represent mean \pm SD from pooled samples of 4-5 independent experiments with multiple PBMC and MAPC cell donors. Statistical analysis was performed using One-way ANOVA with a Tukey's multiple comparison test in reference to the control PBMC alone $\left(* \star \star \star p<0.0001, * \star \star p<0.001\right.$, and $\left.{ }^{*} p<0.05\right)$. 
TGF $\beta 1$
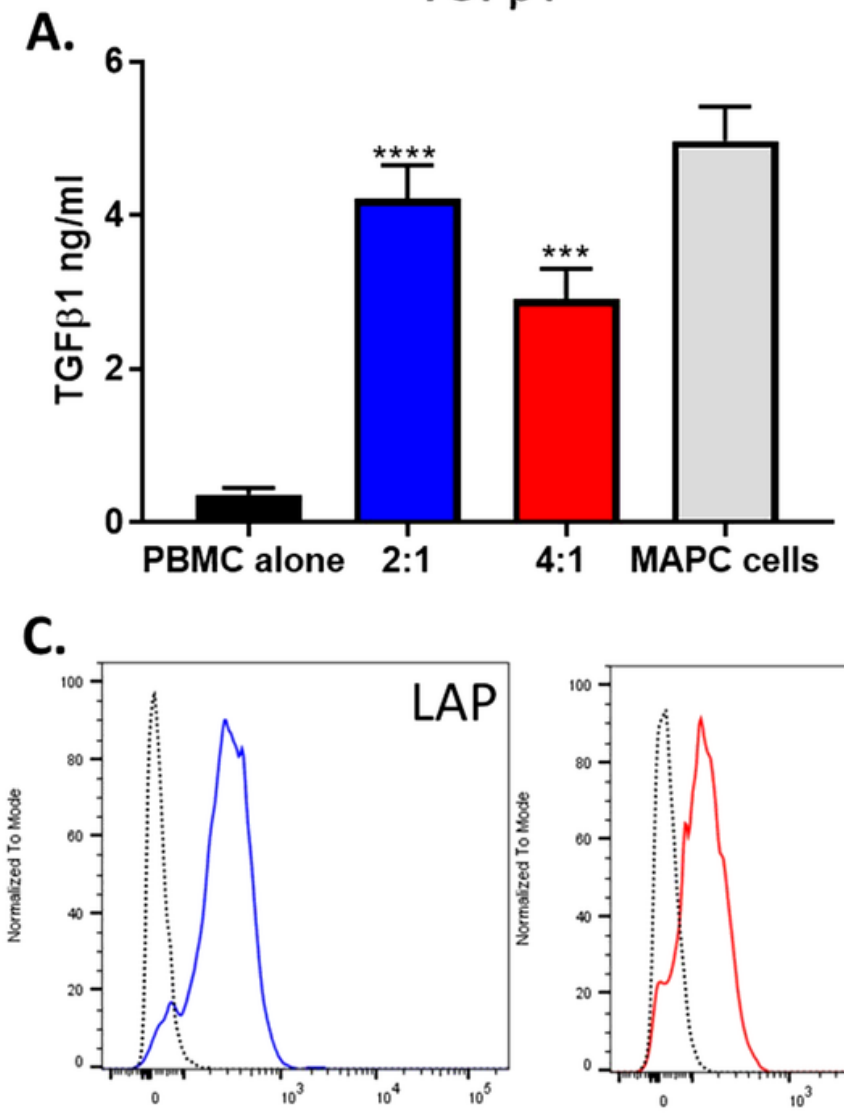
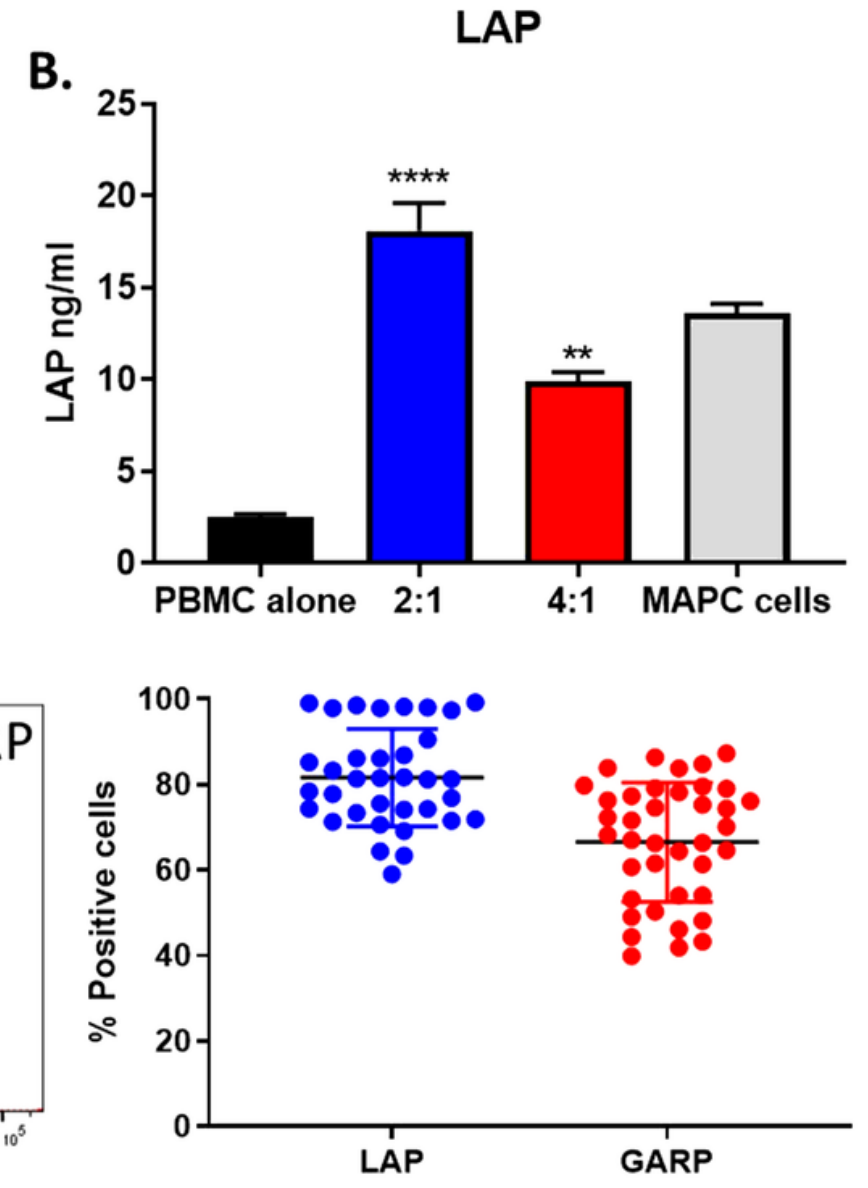

Figure 4

\section{Figure 4}

MAPC cells secrete high levels of TGFB1. (A) TGFB1 and (B) LAP concentrations in supernatants from 7day cultures of PBMC alone (black), 2:1 (blue) and 4:1 (red) PBMC: MAPC cells, and MAPC cells alone (gray) measured by ELISA. MAPC cells were plated alone at 2:1 equivalent cell number. (C) LAP (blue) and GARP (red) surface expression on MAPC cells determined by flow cytometry. FMO shown as dotted black line. Graph showing quantification of LAP (blue) and GARP (red) surface expression on MAPC cells. Data represent mean \pm SD from pooled samples of multiple independent experiments. Statistical analysis was performed using One-way ANOVA with a Tukey's multiple comparison test reference to the control PBMC alone $\left({ }^{\star \star \star *} p<0.0001, * \star \star p<0.001\right.$, and $\left.{ }^{* \star} p<0.01\right)$. 

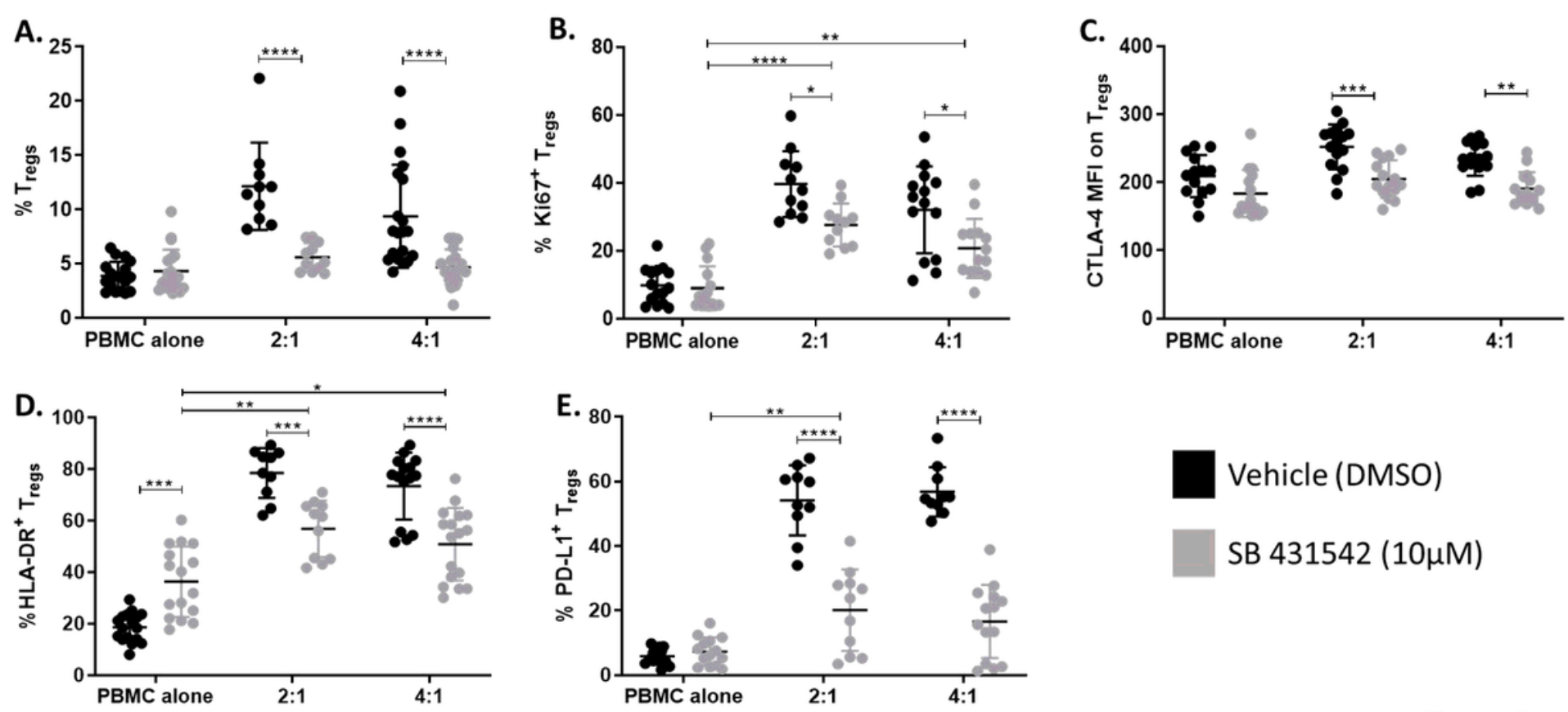

Figure 5

Figure 5

Inhibition of TGF $\beta$ decreases MAPC cell mediated induction of Tregs. (A) Quantification of Treg percentages after 7-day co-culture with MAPC cells in the presence of vehicle (DMSO, black) or SB

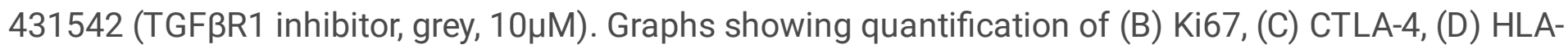
DR, and (E) PD-L1 expression on Tregs. Data represent mean \pm SD from pooled samples of multiple independent experiments. Statistical analysis was performed using Two-way ANOVA with a Sidak's multiple comparison test $\left({ }^{\star \star \star *} p<0.0001,{ }^{* \star *} p<0.001,{ }^{* *} p<0.01\right.$, and $\left.{ }^{*} p<0.05\right)$. 

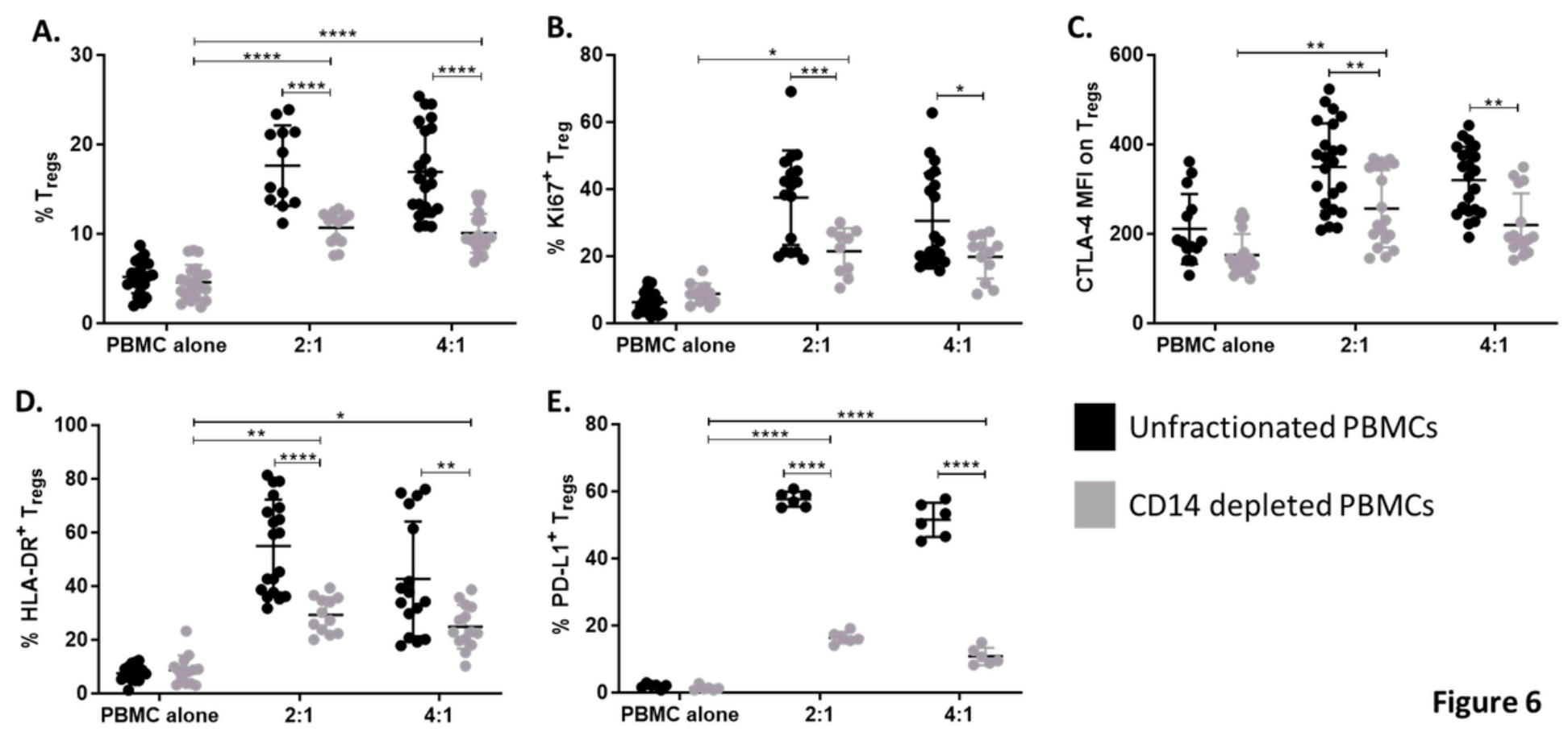

Figure 6

Figure 6

CD14+ monocytes are required for optimal MAPC cell induction of Tregs. (A) Quantification of Treg percentages after 7-day co-culture of unfractionated PBMCs (black) or CD14 depleted PBMCs (grey) with MAPC cells. Graphs showing quantification of (B) Ki67, (C) CTLA-4, and (D) HLA-DR, and (E) PD-L1. Data represent mean \pm SD from pooled samples of multiple independent experiments. Statistical analysis was performed using Two-way ANOVA with a Sidak's multiple comparison test $\left({ }^{\star \star *} \mathrm{p}<<0.0001,{ }^{\star \star \star} \mathrm{p}<0.001\right.$; ${ }^{*} \mathrm{p}<0.01$, and $\left.{ }^{*} \mathrm{p}<0.05\right)$. 

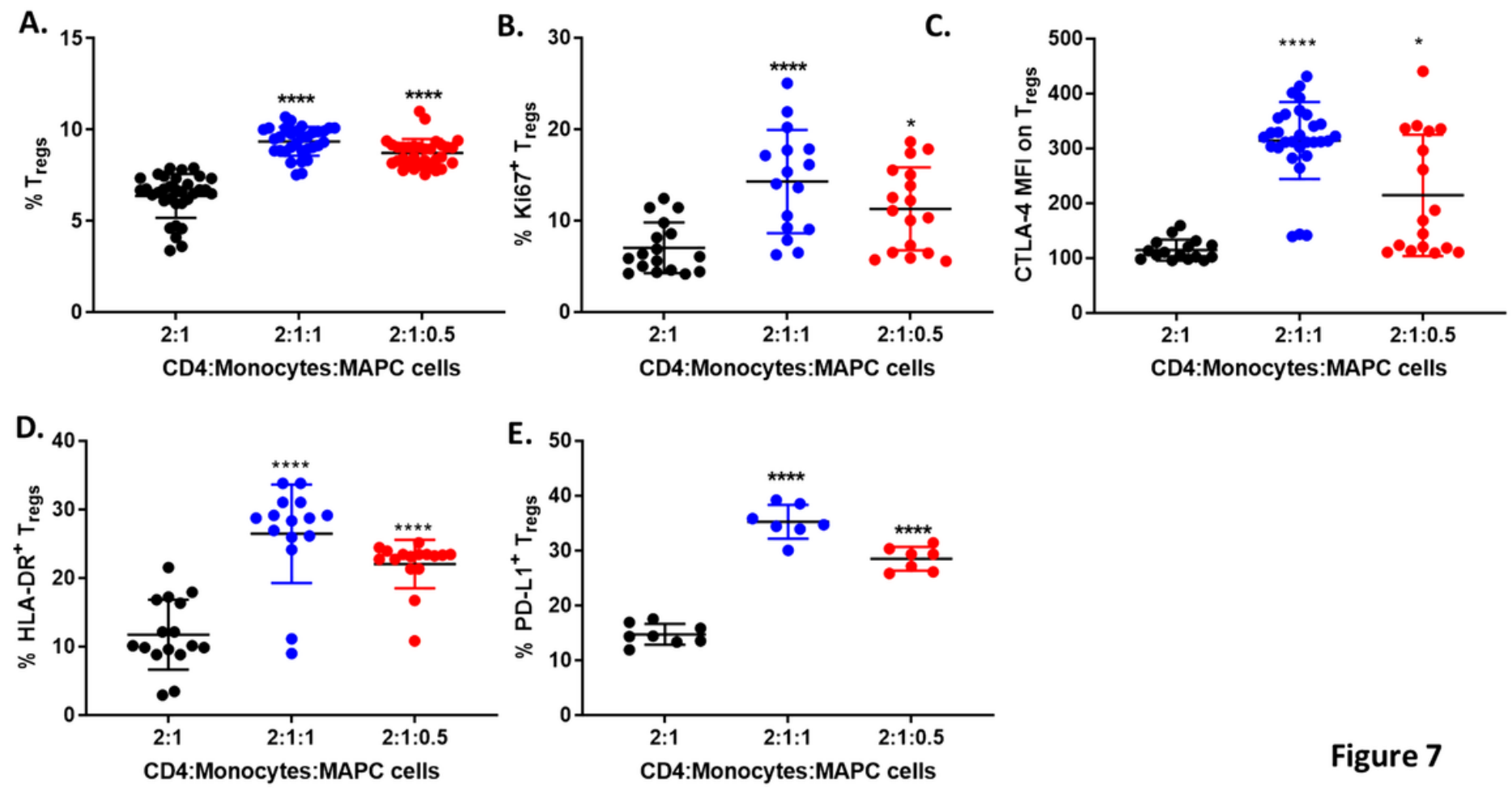

Figure 7

Figure 7

Co-culture of isolated CD4+ T cells and CD14+ monocytes with MAPC cells induce Treg. (A)

Quantification of Treg percentages after 7-day co-culture of isolated CD4+ T cells and CD14+ monocytes (2:1 CD4+ T cell: CD14+ monocytes) with MAPC cells at 2:1:1 (blue) or 2:1:0.5 (red). Graphs showing quantification of (B) Ki67, (C) CTLA-4, (D) HLA-DR, and (E) PD-L1 expression on Tregs. Data represent mean \pm SD from pooled samples of multiple independent experiments. Statistical analysis was performed using Two-way ANOVA with a Tukeys's multiple comparison test $\left(* \star \star \star p<0.0001\right.$ and $\left.{ }^{*} p<0.05\right)$. 
A.

PBMC: MAPC Cell

Co-culture

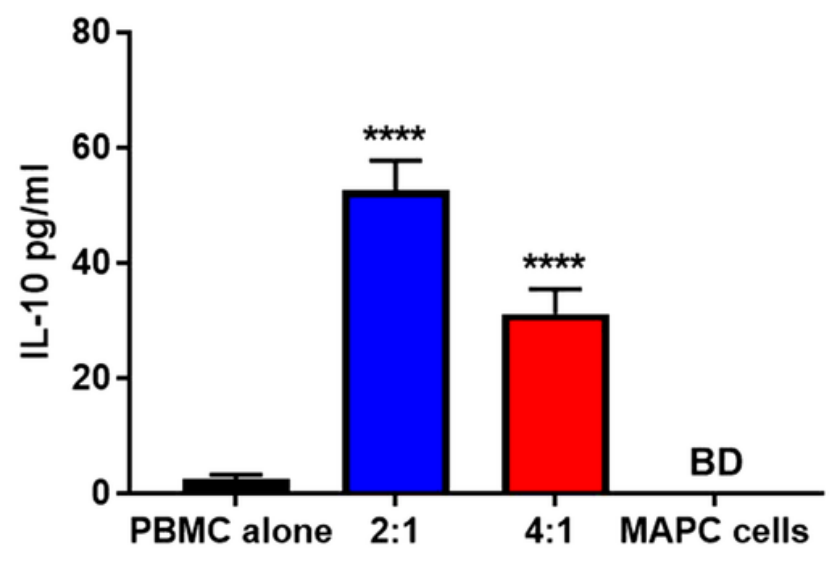

C.

Isolated CD4: Monocyte: MAPC Cell

Co-culture

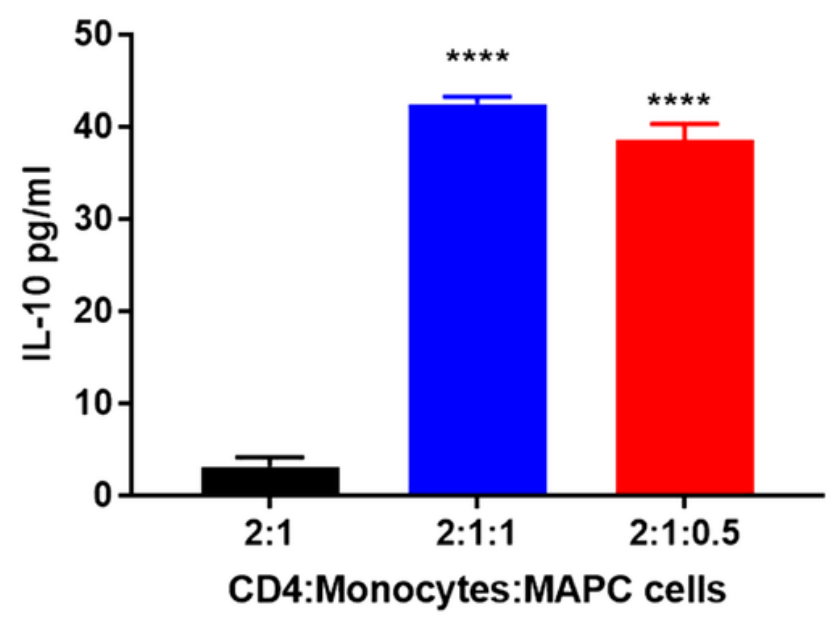

B. CD14-depleted PBMC: MAPC Cell Co-culture

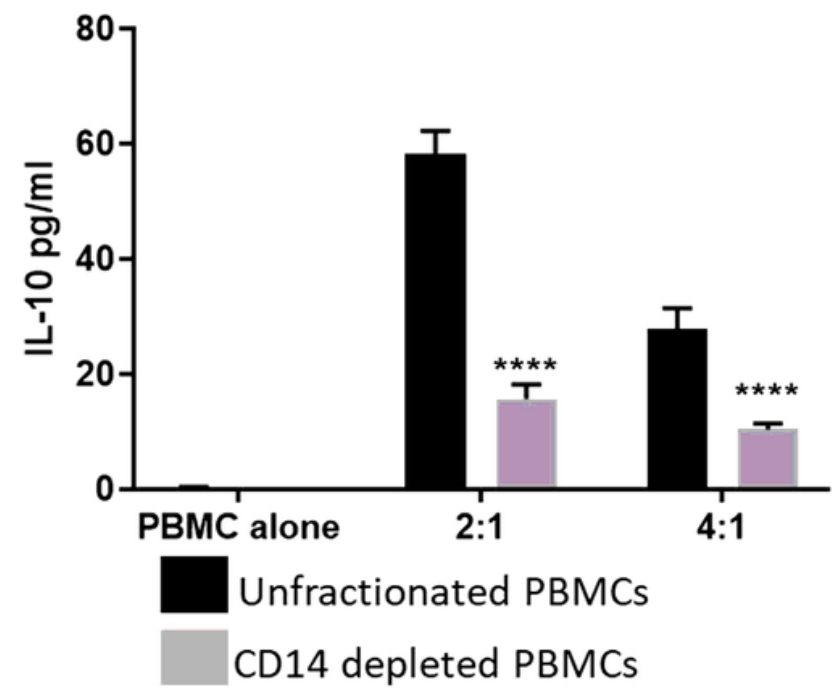

Figure 8

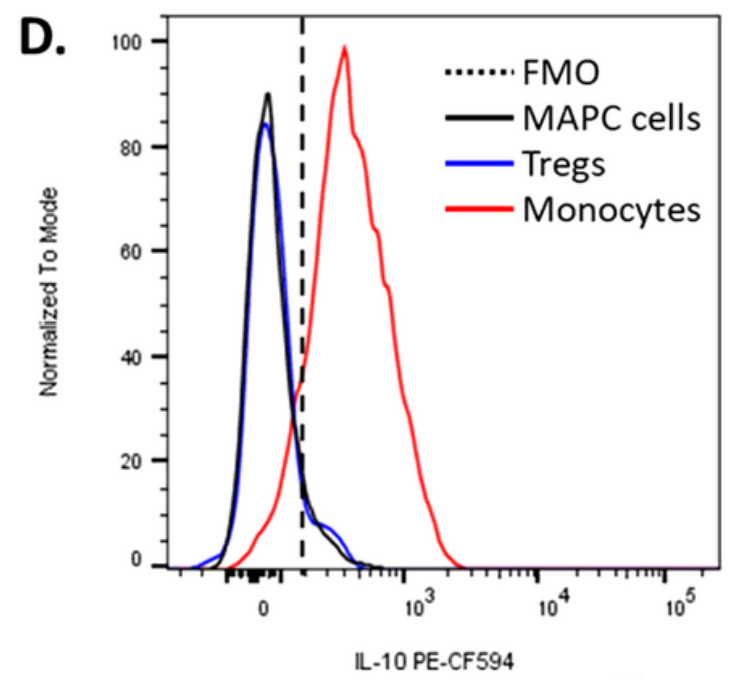

Figure 8

MAPC cells promotes monocyte secretion of IL-10. (A) IL-10 concentration in cultures supernatants of PBMC alone (black), 2:1 (blue) and 4:1 (red) PBMC: MAPC cells, and MAPC cells alone (gray) (BD, below detection) measured by ELISA. (B) IL-10 levels in supernatants collected from PBMCs (black) or CD14 depleted PBMCs (gray) cultured alone or with MAPC at 2:1 and 4:1 PBMC: MAPC ratios for 7 days measured by ELISA. Statistical analysis was performed using Two-way ANOVA with a Sidak's multiple comparison test $(* \star \star \star p<0.0001)$ (C) IL-10 concentration in supernatants from cultures of isolated CD4+ T cells and CD14+ monocytes (2:1 CD4+ cell: CD14+ monocytes) with MAPC cells at 2:1:1 (blue) or 2:1:0.5 (red) measured by ELISA. Data represent mean \pm SD from pooled samples of multiple independent 
experiments. Statistical analysis was performed using Two-way ANOVA with a Tukeys's multiple comparison test $(* \star \star \star p<0.0001)$.

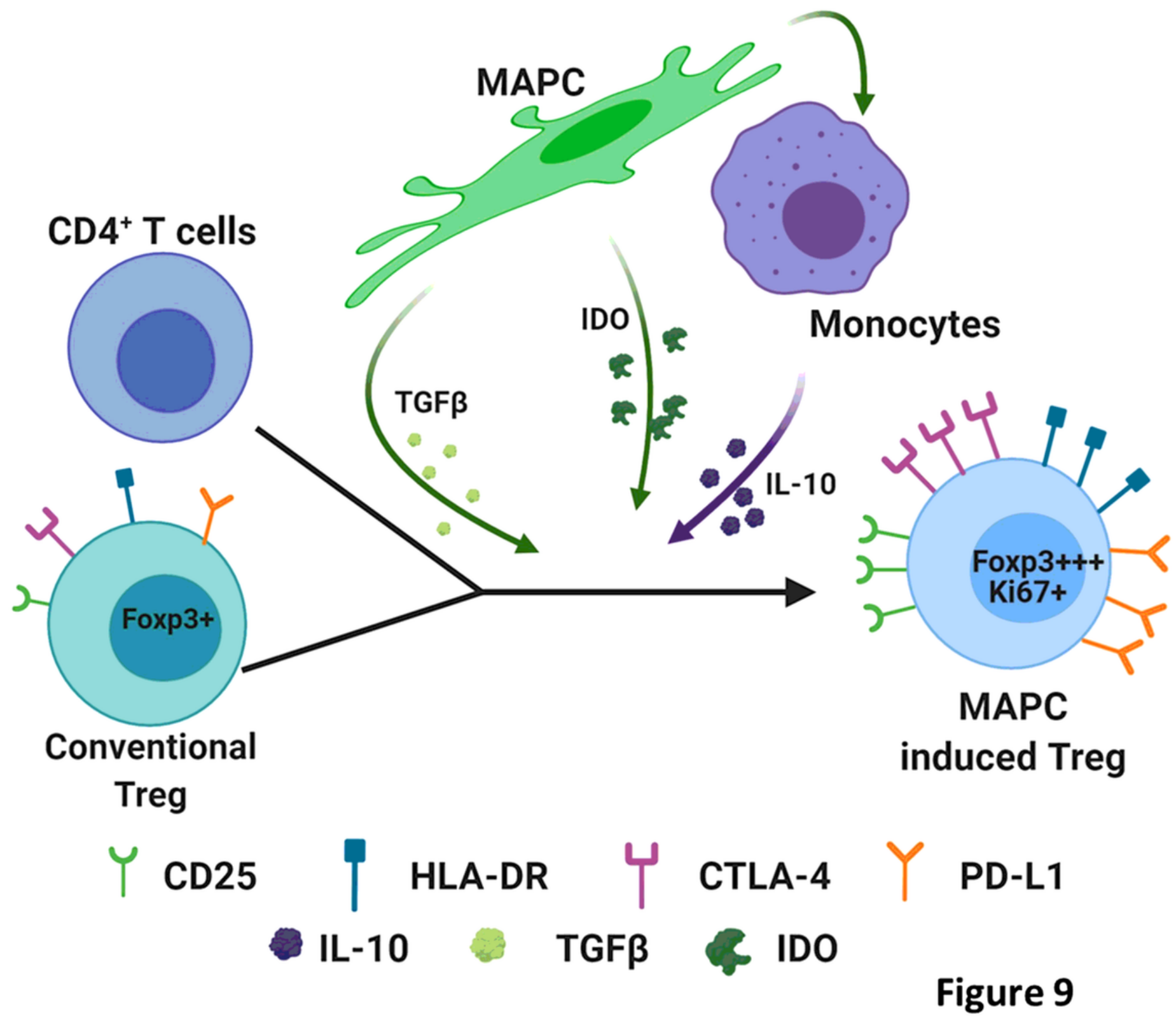

Figure 9

MAPC cell induction of Tregs. Interactions between MAPC cells and Tregs promote Treg expansion and enhance Treg suppressive function characterized by increased expression of CTLA-4, HLA-DR, and PD-L1. Additionally, MAPC cells drive the conversion of CD4+ T cells into Tregs via secretion of TGF $\beta$ and IDO, as well as interactions with CD14+ monocytes, which in turn secrete IL-10. Created using Biorender.com.

\section{Supplementary Files}

This is a list of supplementary files associated with this preprint. Click to download. 
- SupFig1.jpg

- SupFig2.jpg

- SupFig3.jpg

- SupFig4.jpg

- SupFig5.jpg 